\title{
Development of a multi-scale simulation model of tube hydroforming for superconducting RF cavities
}

\author{
H. S. Kim ${ }^{1, *}$, M. D. Sumption ${ }^{1}$, H. J. Bong ${ }^{1}$, H. Lim ${ }^{2}$, and E.W. Collings ${ }^{1}$ \\ ${ }^{1}$ Dept. of Materials Science and Engineering, The Ohio State University, Columbus, OH, USA \\ ${ }^{2}$ Sandia National Laboratories, Albuquerque, NM, USA. \\ *Corresponding author: M. D. Sumption, Tel: +1 (614) 688-3604, Fax: +1 (614) 292-1537, Email: \\ sumption.3@osu.edu
}

\begin{abstract}
This work focuses on finite element modeling of the hydroforming process for niobium tubes intended for use in superconducting radio frequency (SRF) cavities. The hydroforming of tubular samples into SRF-relevant shapes involves the complex geometries and loading conditions which develop during the deformation, as well as anisotropic materials properties. Numerical description of the process entails relatively complex numerical simulations. A crystal plasticity (CP) model was constructed that included the evolution of crystallographic orientation during deformation as well as the anisotropy of tubes in all directions and loading conditions. In this work we demonstrate a multi-scale simulation approach which uses both microscopic CP and macroscopic continuum models. In this approach a CP model (developed and implemented into ABAQUS using UMAT) was used for determining the flow stress curve only under bi-axial loading in order to reduce the computing time. The texture of the materials obtained using orientation imaging microscopy (OIM) and tensile test data were inputs for this model. Continuum $\mathrm{FE}$ analysis of tube hydroforming using the obtained constitutive equation from the $\mathrm{CP}$ modeling was then performed and compared to the results of hydraulic bulge testing. The results show that high quality predictions of the deformation under hydroforming of $\mathrm{Nb}$ tubes can be obtained using CP-FEM based on their known texture and the results of tensile tests. The importance of the CP-
\end{abstract}


FEM based approach is that it reduces the need for hydraulic bulge testing, using a relatively simple computational approach.

Key words: Hydroforming, tube bulge test, Abaqus, FEM, crystal plasticity, CP-FEM

\section{Introduction}

\subsection{Fabrication of superconducting RF cavities}

Superconducting radio frequency (SRF) cavities provide energy to the particles in high energy particle accelerators. Continuing efforts in terms of fabrication technique are ongoing to improve cavity performance and achieve the needed high accelerating gradients and quality factors [1-3]. Electron-beam (EB) welding is the most common and well-established technique for the fabrication of multi-celled cavities. However, associated with it are some problems that limit cavity performance. Welding provides opportunities for the formation of defects such as foreign material inclusions and topological surface imperfections. Since the RF surface magnetic field is concentrated along the equatorial weld of the cell, the surface quality of the welded region is a major concern. In recent years advanced cavity treatment techniques including electropolishing have permitted accelerating gradients to approach the theoretical limit [4]. However, higher accelerating fields and drastic reductions in cavity production time and costs are needed for the further development of more powerful accelerators. For these reasons, hydroforming, a new seamless weld-free fabrication technique, is being considered as an approach to improve electric field gradients and expedite the fabrication of multi-celled cavities [5-7]. The use of hydroforming would eliminate the multitude of EB welded seams which introduce performance-reducing defects. The resulting reduction in post-process operation, including electropolishing, is expected to reduce 
the manufacturing cost and time for the production of SRF cavities. Hydroforming offers many advantages. The basic mechanical problems have been solved. However, to date the ability to model tube deformation has not been sufficient. Required is a reliable way to model the hydroforming of a tube into a multi-cell cavity that is based on measured materials properties and takes into account the complexities of loading condition and material geometry for tube hydroforming.

\subsection{Evolution of the Modelling Approach}

Our earlier research focused on the determination of the constitutive relationships of hydroformed tubular materials and a prediction of deformation using a continuum model. This approach was based on the acquisition of data from hydraulic bulge testing, figure 1 . We first examined the validity of various analytical models for obtaining the flow stress curve from the tube bulge test results [8]. Subsequently, the constitutive relationships of tubular materials were obtained from the tensile and tube bulge tests using a previous verified and selected analytical model [9]. The continuum numerical simulation analyses were performed using these constitutive equations. The results of the study emphasized the importance of bulge testing, at the time, rather than tensile testing when deriving the constitutional relationships eventually needed for continuum modeling the hydroforming of SRF cavities. We subsequently went on to include the material's anisotropic properties and used an anisotropy coefficient to determine the flow stress curve of anisotropic materials [10]. It was demonstrated that a more accurate flow stress curve can be obtained by considering anisotropic properties.

Although the previous studies showed that the flow stress curve from the tube bulge test represents the more accurate deformation behavior of hydroformed tubular materials rather than 
that from the uniaxial tensile test, there was the divergence between experimental results and numerical simulation at high strain. This may be due to the effect of anisotropy which evolves during the deformation due to the complex SRF-relevant geometry and loading conditions. Therefore, this present study focusses on a simulation strategy which uses a crystal plasticity finite element method (CP-FEM) for analyzing the anisotropy in all directions under various loading conditions. Of course, it is possible to consider the evolution of orientation during deformation as well as anisotropy of tubes in all directions and loading conditions. However, the computing time for the detailed replication of hydroforming applied to the local texture with the additional constrains is very high, and a convergence problem may occur due to the complexity of geometry and loading condition for tube hydroforming [11]. Therefore, this work proposes a multi-scale simulation approach which uses both microscopic CP and macroscopic continuum models. In this approach the $\mathrm{CP}$ model was used only for determining the flow stress curve under bi-axial loading. Continuum FE analysis of tube hydroforming using the obtained constitutive equation from the $\mathrm{CP}$ modeling was then performed. This approach was demonstrated using the results of tensile, bulge tests and microstructural analyses performed on $\mathrm{Cu}$ and $\mathrm{Nb}$ tubes. Tables I and II list the sample dimension, preparation, testing, and numerical simulation analyses performed in this and related studies. Some data from [9] were used in this study.

\section{Outline of the present paper}

Figure 2 shows an outline of the present paper. Three different models were used to simulate the hydroforming process. The first and second are macroscopic continuum models using the constitutive equations (strain - stress relationship) as an input to the simulation. The 
constitutive equations for the first and second models were obtained from the tensile test and bulge test, respectively. The third model is multi-scale simulation using both continuum and CP-FEM models. In it, the constitutive equation was obtained from the microscopic simulation model (CPFEM) using microstructural information (i.e., orientation) of materials from the orientation image mapping (OIM) and tensile test data for determining the material parameters. Continuum FE analysis based on the obtained constitutive equation was then performed. In order to reduce the computing time, a cubic shaped CP model was constructed and an applied bi-axial force replicated the actual stress state during the bulge test. Details of each simulation model are presented in the numerical simulation section.

\section{Experimental}

\subsection{Materials}

Copper $(\mathrm{Cu})$ alloy and niobium $(\mathrm{Nb})$ tubes were used in this study. In order to increase their formability, the $\mathrm{Cu}$ alloy tubes were heat treated at $600{ }^{\circ} \mathrm{C}$ for 1 hour in flowing nitrogen gas containing a small amount of hydrogen in order to prevent oxidation. The $\mathrm{Nb}$ samples (tubes and test coupons) were heat treated under the conditions listed in Table II. One sample was heat treated for $3 \mathrm{~h} / 800^{\circ} \mathrm{C}$, and another for $2 \mathrm{~h} / 1000^{\circ} \mathrm{C}$. Some samples were heat treated multiple times to increase the formability: one was first heat treated for $3 \mathrm{~h} / 800^{\circ} \mathrm{C}$ and then for $2 \mathrm{~h} / 1000^{\circ} \mathrm{C}$ (“ $3 \mathrm{~h} / 800^{\circ} \mathrm{C}+2 \mathrm{~h} / 1000^{\circ} \mathrm{C}$ "), another was heat treated three times for $2 \mathrm{~h} / 1000^{\circ} \mathrm{C}\left(" 2 \mathrm{~h} / 1000^{\circ} \mathrm{C} \mathrm{X3").}\right.$ The experimental tensile and bulge data of $\mathrm{Nb}$ samples heat treated for $2 \mathrm{~h} / 1000^{\circ} \mathrm{C}$ in previous work was used for this study [9]. For the $\mathrm{Nb}$ samples heat treated multiple times, numerical analysis based on the microstructure and tensile test was performed. 


\subsection{Tensile and tube bulge tests}

The samples for tensile tests were directly cut to ASTM-standard dimensions from the tube wall parallel to the tube axis. The obtained engineering strain-stress curves of samples were converted to the true strain-stress curve as input to the simulations.

Figure 3 depicts the tube bulge system including a hard tooling set, hydraulic pressurization system, and data acquisition (DAQ) system. The clamping dies confined the tube deformation when hydraulic pressure was applied. Axial movement of both ends of the tube was prevented by the clamping dies, while the center section of the tube expanded freely. The ends of tubes were sealed by axial punches. Lead foil provided a seal between the punches and the tube. Hydraulic pressure was applied to the inside of sealed tube using an air-assisted hydraulic pump. Hydraulic oil was the pressurization medium. During expansion, the bulge height and the wall thickness at the center of the tube were measured as functions of the internal pressure. A laser sensor and an ultrasonic thickness transducer were used for measuring the bulge height and wall thickness, respectively.

Based on measurements of internal pressure, bulge height, and wall thickness an analytical model was applied to determine the flow stress curves of the tubular materials $[9,12]$. In order to determine the effective strain-stress curve, six parameters should be first determined: The radii of curvature of the bulged region in the longitudinal $\left(R_{Z}\right)$ and circumferential $\left(R_{\theta}\right)$ directions, the longitudinal ( $\left.\sigma_{z}\right)$ and circumferential $\left(\sigma_{\theta}\right)$ stresses, and the circumferential $\left(\varepsilon_{\theta}\right)$ and thickness ( $\varepsilon_{t}$ ) strains. Figure 4 shows the parameters required to determine the stresses and strains.

The radii of curvature of the bulged region in the longitudinal $\left(R_{Z}\right)$ and hoop $\left(R_{\theta}\right)$ directions are determined assuming the bulge is spherical, thus: 


$$
\begin{gathered}
R_{\theta}=R_{0}+\Delta R \\
R_{z}=\left[\left(\frac{w}{2}\right)^{2}+\Delta R^{2}\right] /(2 \Delta R) .
\end{gathered}
$$

where $R_{0}$ is the initial radius of the tube, $\Delta R$ is the bulge height, and $w$ is the width of the bulged region between the clamping dies. Based on the calculated $R_{Z}$ and $R_{\theta}$, the values of $\sigma_{z}$ and $\sigma_{\theta}$ are given by

$$
\begin{gathered}
\sigma_{z}=p R_{\theta} /(2 t), \\
\sigma_{\theta}=\frac{p R_{\theta}}{t}-\frac{\sigma_{z} R_{\theta}}{R_{z}}
\end{gathered}
$$

where $p$ is the internal hydraulic pressure and $t$ is the wall thickness. These equations are derived assuming force equilibrium at the center of the tube. The stress in the thickness direction was ignored. The circumferential $\left(\varepsilon_{\theta}\right)$ and thickness strains $\left(\varepsilon_{t}\right)$ are given by

$$
\begin{gathered}
\varepsilon_{\theta}=\ln \left(R_{\theta} / R_{0}\right), \\
\varepsilon_{t}=\ln \left(t / t_{0}\right) .
\end{gathered}
$$

With these parameters, the effective stress $(\bar{\sigma})$ and strain $(\bar{\varepsilon})$ can be calculated by using the von Mises yield criterion supposing isotropy:

$$
\begin{gathered}
\bar{\sigma}=\sqrt{\sigma_{\theta}^{2}-\sigma_{\theta} \sigma_{z}+\sigma_{z}^{2}}, \\
\bar{\varepsilon}=2 / \sqrt{3} \sqrt{\varepsilon_{\theta}^{2}+\varepsilon_{\theta} \varepsilon_{t}+\varepsilon_{t}^{2}} .
\end{gathered}
$$

After $\bar{\sigma}$ and $\bar{\varepsilon}$ have been determined, they are assembled into a stress-strain relationship of the form

$$
\bar{\sigma}=K \cdot \bar{\varepsilon}^{n}
$$


where $K$ is the strength coefficient, and $n$ is the strain hardening coefficient. These equations represent the constitutive relationship of the materials and provide input to the simulation programs.

\subsection{Microstructural analysis}

The microstructures as well as the textures (crystallographic orientations) of the samples were analyzed. The samples were prepared by standard metallographic techniques, and the orientation of the cross section in a plane parallel to the tube was analyzed using OIM. The average Euler angles of each grain are extracted from the OIM using the associated data analysis software.

\section{Numerical simulation}

\subsection{Macroscopic continuum model}

The macroscopic continuum model used the flow stress curve as input, and a FE model of the tube bulge test was constructed using commercial Abaqus/explicit. The symmetry of the tube was exploited in that a 2-D axisymmetric cross-section was modelled -- and only one half of the tube - which led to a much increased computational efficiency. The axial and radial constraints were applied at the ends of the tube in response to the absence of axial feeding, and friction between the tube blank and the die was neglected. Although axial feeding is necessary during a hydroforming operation, it is customary for the tube ends to be immobilized when performing the

bulge test. Four-noded solid elements (CAX4R) were used for bulge-forming simulation with four element layers through the thickness.

\subsection{Microscopic crystal plasticity model}


In order to consider the influence of the crystallographic texture and its evolution during the deformation of polycrystalline material, a microscopic crystal plasticity $(\mathrm{CP})$ model was constructed using CP-FEM. The crystal constitutive equations based on slip systems and statistical grain orientation information were used to predict the plastic anisotropy and texture evolution during deformation. For numerical convenience, the CP-FEM model $[13,14]$ assumed that plastic deformation occurred by crystallographic slip alone, and other deformation mechanisms such as twinning, diffusion and grain boundary sliding were not considered. In addition, neighboring grain interactions or the presence of grain boundaries were ignored. The linkage of grains was considered by assuming that all grains exhibit identical strain, enforcing inter-grain equilibrium.

The kinematics of the CP approach used for this study is based on the studies of [13, 1518]. The constitutive equation in the single crystal can be expressed using the second PiolaKirchhoff stress, S, and the Lagrangian strain tensor, E, as follows:

$$
\begin{gathered}
\mathrm{S}=\mathrm{C}^{\mathrm{e}}: \mathrm{E}=\operatorname{det}\left(\mathrm{F}^{e}\right) \mathrm{F}^{e-1} \sigma \mathrm{F}^{e-T}, \\
\mathrm{E}=\frac{1}{2}\left(\mathrm{~F}^{e T} \mathrm{~F}^{e}-1\right)
\end{gathered}
$$

where $\mathrm{C}^{\mathrm{e}}$ is the fourth order elastic constant matrix and $\sigma$ is the Cauchy stress.

The CP constitutive equation is determined by dislocation glide [14]. The deformation gradient consists of elastic and plastic parts:

$$
\mathrm{F}=\mathrm{F}^{e} \mathrm{~F}^{p}
$$

where $\mathrm{F}^{e}$ and $\mathrm{F}^{p}$ define elastic distortion of the lattice and dislocation glide on the crystal slip plane, respectively. The rate of the plastic part of the deformation gradient $\dot{\mathrm{F}}^{p}$, is defined as

$$
\dot{\mathrm{F}}^{p}=\overline{\mathrm{L}}^{p} \mathrm{~F}^{p}
$$


where $\overline{\mathrm{L}}^{p}$ is the plastic velocity gradient. This gradient is related to the glide on the slip system with slip plane $\alpha$, slip plane normal $\mathrm{n}_{0}{ }^{(\alpha)}$, and slip direction ${s_{0}}^{(\alpha)}$ as follows $[18,19]$ :

$$
\overline{\mathrm{L}}^{p}=\sum_{\alpha=1}^{n} \dot{\gamma}^{(\alpha)}{s_{0}}^{(\alpha)} \mathrm{xn}_{0}{ }^{(\alpha)}
$$

where $\dot{\gamma}^{(\alpha)}$ is the rate of plastic shear on slip system $\alpha$, and $n$ is total number of slip systems.

The rate of shear on slip system $\alpha$ is described by a power low function of the resolved shear stress as follows $[13,20]$ :

$$
\dot{\gamma}^{(\alpha)}=\dot{\gamma}_{0}\left(\frac{\tau^{(\alpha)}}{g^{(\alpha)}}\right)^{1 / m} \sin \left(\tau^{(\alpha)}\right)
$$

where $\dot{\gamma}_{0}$ is a reference shear rate, $\tau^{(\alpha)}$ is the resolved shear stress on slip system $\alpha, g^{(\alpha)}$ is slip resistance, and $m$ is strain rate sensitivity [21,22].

The slip resistance $g^{(\alpha)}$ in slip system $\alpha$ evolves during the deformation. It has an initial value of $g_{0}$ and changes as a function of plastic strain on all slip systems $\beta$ according to

$$
\dot{g}^{(\alpha)}=\sum_{\beta=1}^{n} h_{\alpha \beta}\left|\dot{\gamma}^{(\beta)}\right|
$$

where $h_{\alpha \beta}$ is the hardening coefficient matrix representing the interactions of dislocation in different slip planes. It can be expressed by

$$
\begin{gathered}
h_{\alpha \beta}=h_{\beta}\left(q_{\text {self }}+\left(q_{\text {self }}-q_{\text {lat }}\right) \delta_{\alpha \beta}\right), \\
h_{\beta}=h_{0}\left(1-\frac{g^{(\beta)}}{g_{s}}\right)^{a}
\end{gathered}
$$


where the $q_{\text {self }}$ and $q_{\text {lat }}$ are self and latent hardening coefficients, respectively [22]. In equation (4.9), $h_{0}$ is a reference self-hardening coefficient, $a$ is a hardening exponent, and $g_{s}$ is a saturated flow stress.

The above materials parameters of $h_{0}, g_{0}, g_{s}$ and $a$ determine the strain-stress response and the evolution of texture. These parameters are inputs to CP-FEM for materials properties. An inverse procedure is implemented to obtain the materials parameters. The simulations are iterated to find the materials parameters yielding the simulation results best fitted to the experimental strain-stress responses. The uniaxial tensile test curve of the polycrystalline sample was used to fit the materials parameters because of difficulty in obtaining single crystal tensile behavior. In this study, the tensile test results of the samples cut from the tube wall parallel to the tube axis were used to find best-fit parameters.

The above CP model was implemented using the commercial Abasqus/Standard with user material properties (UMAT) using a fortran code [22]. For a simplicity, factors not considered were: (1) the effect of grain size on yield stress and work hardening, (2) the spatial arrangement of orientation, and (3) elastic anisotropy.

A simple cube shaped model was constructed to obtain the flow stress curve under bi-axial loading. The initial inputs for this model are the materials parameters $\left(h_{0}, g_{0}, g_{s}\right.$ and a) and the crystal orientations $(\varphi, \theta$ and $\psi)$. In order to determine the materials parameters, the tensile test result of the sample from the tube in the axial direction was used for a reference polycrystalline behavior. The best-fit material parameters were used as an input to the simulation as mentioned before. In order to represent the initial crystallographic texture without losing the original characteristic grain distribution, the OIM image was divided into 1000 equal parts, and the one set 
of Euler angles was extracted from one part. The number of orientations used in this model was 1000. It assumed that this local microstructure distribution is globally representative. Twelve slip systems of $\{111\}<110>$ were operating in $\mathrm{Cu}$ with its face centered cubic (FCC) crystal structure. For $\mathrm{Nb}$ with its body centered cubic crystal structure (BCC), a total of 24 slip systems consisting of 12 systems of $\{110\}<111>$ and 12 systems of $\{112\}<111>$ were defined. The slip systems of $\{123\}(111)$ activated by substitutional impurities were not included [23].

\section{Results}

\subsection{Constitutive equations}

Figure 5 shows engineering strain-stress curves of $\mathrm{Cu}$ and $\mathrm{Nb}$ samples obtained from the tensile tests. These results were converted to true strain-stress data for use as input to the simulation.

Figure 6 depicts the deformed $\mathrm{Cu}$ tube after bulge testing. During the test, the pressure, bulge height and wall thickness were recorded. Using these data, the corresponding flow stress curves were determined using the analytical model described above.

Figure 7 shows the orientation maps of the $\mathrm{Cu}$ and $\mathrm{Nb}$ tubes. The $\mathrm{Cu}$ tube has a uniform microstructure with no strong preferred grain orientation, figure $7(\mathrm{a})$. The microstructure of $\mathrm{Nb}$ was non-uniform through the thickness and evidently was not fully recrystallized even after

multiple heat treatments, figure 7(b). The rolling used in the fabrication of the $\mathrm{Nb}$ tubes presumably contributed to a non-uniform distribution of plastic strain through the thickness, which led to an inhomogeneous driving force of recrystallization. The first heat treatment annealed out some of the included cold work strain and as a result raised the recrystallization temperature. Therefore, 
recrystallization did not occur in the following heat treatment. In order to obtain the recrystallized structure, a higher temperature HT would be required.

Figures $8 \sim 12$ show pole figures of measured and selected orientations of $\mathrm{Cu}$ heat treated for $1 \mathrm{~h} / 600^{\circ} \mathrm{C}$, and $\mathrm{Nb}$ heat treated for $3 \mathrm{~h} / 800^{\circ} \mathrm{C}, 2 \mathrm{~h} / 1000^{\circ} \mathrm{C}, 3 \mathrm{~h} / 800^{\circ} \mathrm{C}+2 \mathrm{~h} / 1000^{\circ} \mathrm{C}$ and $2 \mathrm{~h} / 1000^{\circ} \mathrm{C}$ $\mathrm{X} 3$, respectively. In order to reduce the computing time of CP-FEM, one thousand orientations in terms of Euler angles were selected from the measured orientations to represent the initial orientation of the sample for CP-FEM simulation. The very small differences between the pole figures of the measured and selected orientations, indicated that the selected orientations represented the measured orientations without loss of characteristic grain distribution in a statistical sense.

In order to obtain the flow stress curve from CP-FEM, the materials parameters as inputs were first determined. Table III lists the best-fit materials parameters for CP-FEM yielding the flow stress curve under uniaxial force equivalent to the experimental tensile test. Using these numbers, the flow stress curve under bi-axial force was obtained using CP-FEM and fitted.

The effective flow stress curves obtained from tensile testing, bulge testing, and CP-FEM for $\mathrm{Cu}$ heat treated for $1 \mathrm{~h} / 600^{\circ} \mathrm{C}$ and $\mathrm{Nb}$ heat treated for $2 \mathrm{~h} / 1000^{\circ} \mathrm{C}$ are shown in figures 13 and 14, respectively. Table IV shows the corresponding $K$ and $n$ values for the $\mathrm{Cu}$ and the $\mathrm{Nb}$ tubes. Based on these values, the macroscopic continuum bulge-test simulations ("macroscopic models") were implemented. Figure 15 shows the flow stress curves obtained from the tensile testing and CP-FEM of $\mathrm{Nb}$ samples heat treated for $3 \mathrm{~h} / 800^{\circ} \mathrm{C}, 3 \mathrm{~h} / 800^{\circ} \mathrm{C}+2 \mathrm{~h} / 1000^{\circ} \mathrm{C}$, and $2 \mathrm{~h} / 1000^{\circ} \mathrm{C} \mathrm{X} 3$, respectively. A summary of plastic properties for use as inputs to the macroscopic models for these $\mathrm{Nb}$ tubes is given in Table VI. 


\subsection{Continuum simulation}

Figure 16 show the contour of von Mises stress at pressure of 13.5 and $11.5 \mathrm{MPa}$ for $\mathrm{Cu}$ and $\mathrm{Nb}$ heat treated for $2 \mathrm{~h} / 1000^{\circ} \mathrm{C}$, respectively. Figure 17 shows the bulge-test simulation results for $\mathrm{Nb}$ samples heat treated for $3 \mathrm{~h} / 800^{\circ} \mathrm{C}, 3 \mathrm{~h} / 800^{\circ} \mathrm{C}+2 \mathrm{~h} / 1000^{\circ} \mathrm{C}$, and $2 \mathrm{~h} / 1000^{\circ} \mathrm{C} \mathrm{X} 3$, respectively. In each figure, the simulation results based on the constitutive equations obtained from tensile test and CP-FEM simulation were compared. As expected, the simulation results were different because the multi-scale simulation considered the multi-axial loading and anisotropic properties while the simulation results based on the tensile test represented the deformation behavior under uniaxial loading.

\section{Simulations based on tensile testing, bulge testing, and CP-FEM}

Figure 18 shows the experimental and simulation results the bulge testing of $\mathrm{Cu}$ and $\mathrm{Nb}$ tubes heat treated for $1 \mathrm{~h} / 600^{\circ} \mathrm{C}$ and $2 \mathrm{~h} / 1000^{\circ} \mathrm{C}$, respectively. In order to evaluate the reliability of each model, the experimental results were compared with the macroscopic simulation results based on the constitutive equations obtained from tensile test, bulge test, and CP-FEM simulation. The result for the $\mathrm{Cu}$ alloy tube shows that the flow stress curve from the bulge test represent more accurate deformation behavior rather than the flow stress curve from the tensile test. Due to the multi-axial stress state of bulge test it is more accurate to obtain the flow stress curve from the bulge test rather than the uniaxial tensile test. However, the bulge-based numerical simulation and experimental results tend to diverge at pressures above about $10 \mathrm{MPa}$.. This may be caused both by anisotropic properties as well as localized deformation as the pressure reaches the burst pressure. During the calculation of the flow stress curve using the analytical model, it is assumed 
that the material is isotropic. However, the orientation of the material will change during deformation, therefore, under large strains it may deviate from isotropy. In order to obtain a more accurate flow stress curve, anisotropic property change during deformation behavior should be considered. The numerical simulation results based on CP-FEM are well-matched to the experimental data. The CP-FEM approach considers the orientation and evolution of texture during deformation. Therefore, it seems that the flow curve generated by the CP FEM simulation represent more accurate deformation behavior. For the $\mathrm{Nb}$ tube heat treated for $2 \mathrm{~h} / 1000^{\circ} \mathrm{C}$, the simulation results based on both bulge test and CP-FEM are well matched to the experimental results.

\section{Summary}

This work focuses on finite element modeling of the hydroforming process for niobium tubes intended for use in superconducting radio frequency (SRF) cavities. A crystal plasticity (CP) model was constructed that included the evolution of crystallographic orientation during deformation as well as the anisotropy of tubes in all directions and loading conditions. In this work we demonstrate a multi-scale simulation approach which uses both microscopic $\mathrm{CP}$ and macroscopic continuum models. In this approach a CP model (developed and implemented into ABAQUS using UMAT) was used for determining the flow stress curve only under bi-axial loading in order to reduce the computing time. The texture of the materials obtained using orientation imaging microscopy (OIM) and tensile test data were inputs for this model. Continuum FE analysis of tube hydroforming using the obtained constitutive equation from the CP modeling was then performed and compared to the results of hydraulic bulge testing. 
The constitutive equation developed using CP-FEM based on measured orientation information yields a simulation that agrees well with the experimental results. Therefore, a simulation strategy using a combination of continuum and CP models will accurately describe the deformation behavior of tube materials. Such a strategy based on the experimental results of tensile and microstructure analysis can reduce the need for hydraulic bulge testing and contribute to a reduction in time and costs for SRF cavity development.

\section{Acknowledgements}

We thank Dr. Lance D. Cooley for selecting the Nb tube heat treatment conditions and arranged for the heat treatments to be carried out at the Fermi National Accelerator Laboratory, Batavia, IL, USA. The research was supported by the United States Department of Energy, Office of High Energy Physics, under grant No. DE-SC0004217.

\section{References}

[1] H. Padamsee, "Accelerating applications of RF superconductivity - Success stories," IEEE Transactions on Applied Superconductivity, vol. 15, pp. 2432-2439, Jun 2005.

[2] H. Padamsee, "The science and technology of superconducting cavities for accelerators," Superconductor Science and Technology, vol. 14, pp. R28-R51, 2001.

[3] P. Schmüser, "Basic principles of RF superconductivity and superconducting cavities," CERN Accelerator School, pp. 1-19, 2006.

[4] L. D. Cooley, D. Burk, C. Cooper, N. Dhanaraj, M. Foley, D. Ford, et al., "Impact of Forming, Welding, and Electropolishing on Pitting and the Surface Finish of SRF Cavity Niobium," IEEE Transactions on Applied Superconductivity, vol. 21, pp. 2609-2614, 2011.

[5] V. Palmieri, "Seamless cavities: the most creative topic in RF Superconductivity," in the 8th Workshop on RF Superconductivity, Italy, 1997, pp. 553

[6] W. Singer, X. Singer, I. Jelezov, and P. Kneisel, "Hydroforming of elliptical cavities," Physical Review Special Topics-Accelerators and Beams, vol. 18, p. 22, Feb 2015.

[7] V. Palmieri, "Metal forming technology for the fabrication of seamless Superconducting radiofrequency cavities for particle accelerators," MATEC Web of Conferences, vol. 21, p. 04015, 2015. 
[8] H. S. Kim, M. D. Sumption, H. Lim, and E. W. Collings, "Analysis of materials properties of niobium tube from the results of a virtual bulge test," in Advances in Cryogenic Engineering, Vol 58 (AIP Conference Proc. 1435) 2012, pp. 305-312.

[9] H. S. Kim, M. D. Sumption, M. A. Susner, H. Lim, and E. W. Collings, "Bulge testing of copper and niobium tubes for hydroformed RF cavities," Materials Science \& Engineering A, vol. 654, pp. 13-20, 2016.

[10] H. S. Kim, M. D. Sumption, H. Lim, and E. W. Collings, "Evaluation of Mechanical Properties of Tubular Materials With Hydraulic Bulge Test for Superconducting Radio Frequency (SRF) Cavities," Applied Superconductivity, IEEE Transactions on, vol. 23, pp. 3500604, 2013.

[11] Y. Guan, F. Pourboghrat, and F. Barlat, "Finite element modeling of tube hydroforming of polycrystalline aluminum alloy extrusions," International Journal of Plasticity, vol. 22, pp. 2366-2393, 2006.

[12] M. Koç and T. Altan, "On the characteristics of tubular materials for hydroformingexperimentation and analysis," International Journal of Machine Tools and Manufacture, vol. 41, pp. 761-772, 2001.

[13] D. Peirce, R. Asaro, and A. Needleman, "An analysis of nonuniform and localized deformation in ductile single crystals," Acta Metallurgica, vol. 30, pp. 1087-1119, 1982.

[14] R. J. Asaro and A. Needleman, "Overview no. 42 Texture development and strain hardening in rate dependent polycrystals," Acta Metallurgica, vol. 33, pp. 923-953, 1985.

[15] R. J. Asaro and J. Rice, "Strain localization in ductile single crystals," Journal of the Mechanics and Physics of Solids, vol. 25, pp. 309-338, 1977.

[16] R. Hill and J. Rice, "Constitutive analysis of elastic-plastic crystals at arbitrary strain," Journal of the Mechanics and Physics of Solids, vol. 20, pp. 401-413, 1972.

[17] E. H. Lee, "Elastic-plastic deformation at finite strains," Journal of Applied Mechanics, vol. 36, pp. 1-6, 1969.

[18] J. R. Rice, "Inelastic constitutive relations for solids: an internal-variable theory and its application to metal plasticity," Journal of the Mechanics and Physics of Solids, vol. 19, pp. $433-455,1971$.

[19] R. J. Asaro, "Micromechanics of Crystals and Polycrystals," in Advances in Applied Mechanics. vol. Volume 23, W. H. John and Y. W. Theodore, Eds., ed: Elsevier, 1983, pp. $1-115$.

[20] J. Hutchinson, "Bounds and self-consistent estimates for creep of polycrystalline materials," in Proceedings of the Royal Society of London A: Mathematical, Physical and Engineering Sciences, vol 348, pp. 101-127, 1976.

[21] C. Bronkhorst, S. Kalidindi, and L. Anand, "Polycrystalline plasticity and the evolution of crystallographic texture in FCC metals," Philosophical Transactions of the Royal Society of London A: Mathematical, Physical and Engineering Sciences, vol. 341, pp. 443-477, 1992.

[22] S. R. Kalidindi, C. A. Bronkhorst, and L. Anand, "Crystallographic texture evolution in bulk deformation processing of FCC metals," Journal of the Mechanics and Physics of Solids, vol. 40, pp. 537-569, 1992.

[23] A. Siddiq and S. Schmauder, "Crystal plasticity parameter identification procedure for single crystalline material during deformation," Journal of Computational and Applied Mechanics, vol. 7, pp. 1-15, 2006. 


\section{List of Tables}

Table I Dimensions of starting $\mathrm{Cu}$ alloy and $\mathrm{Nb}$ tubes

Table II Materials, experiments, and numerical simulations included in this and related [9] studies

Table III Material parameters for CP-FEM

Table IV Summary of plastic properties for inputs to the macroscopic model for the $\mathrm{Cu}$ and $\mathrm{Nb}$ tubes

Table V Summary of plastic properties for inputs to the macroscopic model for $\mathrm{Nb}$ heat treated at various conditions 


\section{List of Figures}

Figure 1. Evolution of our research on the hydroforming of tubular materials

Figure 2. Outline of the present paper

Figure 3. Tube bulge test system

Figure 4. Parameters for the analysis of the bulge test results

Figure 5. Tensile test results for (a) $\mathrm{Cu}$ alloy and (b) $\mathrm{Nb}$ samples

Figure 6. The deformed $\mathrm{Cu}$ alloy tube after bulge testing

Figure 7. Orientation maps of (a) $\mathrm{Cu}$ alloy heat treated for $1 \mathrm{~h} / 600^{\circ} \mathrm{C}$, and (b) $\mathrm{Nb}$ heat treated at various conditions

Figure 8. Pole figures of the $\mathrm{Cu}$ alloy heat treated for $1 \mathrm{~h} / 600^{\circ} \mathrm{C}$ : (a) measured and (b) selected orientations

Figure 9. Pole figures of the $\mathrm{Nb}$ heat treated for $3 \mathrm{~h} / 800^{\circ} \mathrm{C}$ : (a) measured and (b) selected orientations [8]

Figure 10. Pole figures of the $\mathrm{Nb}$ heat treated for $2 \mathrm{~h} / 1000^{\circ} \mathrm{C}$ : (a) measured and (b) selected orientations [8]

Figure 11. Pole figures of the $\mathrm{Nb}$ heat treated for $3 \mathrm{~h} / 800^{\circ} \mathrm{C}+2 \mathrm{~h} / 1000^{\circ} \mathrm{C}$ : (a) measured and (b) selected orientations

Figure 12. Pole figure of the $\mathrm{Nb}$ heat treated for $2 \mathrm{~h} / 1000^{\circ} \mathrm{C} \mathrm{X} 3$ : (a) measured and (b) selected orientations

Figure 13. Effective strain-stress curves obtained from the tensile testing, bulge testing and $\mathrm{CP}$ FEM simulation of $\mathrm{Cu}$ alloy heat treated for $1 \mathrm{~h} / 600^{\circ} \mathrm{C}$

Figure 14. Effective strain-stress curves obtained from the tensile testing, bulge testing and CPFEM simulation of $\mathrm{Nb}$ heat treated for $2 \mathrm{~h} / 1000^{\circ} \mathrm{C}$

Figure 15. Effective strain-stress curves obtained from the tensile testing and CP-FEM simulation of $\mathrm{Nb}$ heat treated for (a) $3 \mathrm{~h} / 800^{\circ} \mathrm{C}$, (b) $3 \mathrm{~h} / 800^{\circ} \mathrm{C}+2 \mathrm{~h} / 1000^{\circ} \mathrm{C}$ and (c) $2 \mathrm{~h} / 1000^{\circ} \mathrm{C} \mathrm{X} 3$

Figure 16. Contour of von Mises stress of (a) $\mathrm{Cu}$ alloy and (b) $\mathrm{Nb}$ heat treated for $2 \mathrm{~h} / 1000^{\circ} \mathrm{C}$ 
Figure 17. Simulation results of $\mathrm{Nb}$ heat treated for (a) $3 \mathrm{~h} / 800^{\circ} \mathrm{C}$, (b) $3 \mathrm{~h} / 800^{\circ} \mathrm{C}+2 \mathrm{~h} / 1000^{\circ} \mathrm{C}$ and (c) $2 \mathrm{~h} / 1000^{\circ} \mathrm{C} \mathrm{X} 3$

Figure 18. Simulation results of (a) $\mathrm{Cu}$ alloy heat treated for $1 \mathrm{~h} / 600^{\circ} \mathrm{C} \mathrm{(b)} \mathrm{Nb}$ heat treated for $2 \mathrm{~h} / 1000^{\circ} \mathrm{C}$ 
Table I Dimensions of starting $\mathrm{Cu}$ alloy and $\mathrm{Nb}$ tubes

\begin{tabular}{ccc}
\hline \hline Length $[\mathrm{mm}]$ & Outer radius $[\mathrm{mm}]$ & Wall thickness $[\mathrm{mm}]$ \\
\hline 240 & 31.75 & 1.65 \\
\hline \hline
\end{tabular}


Table II Materials, experiments, and numerical simulations included in this and related [9] studies

\begin{tabular}{ccccccc}
\hline \hline \multirow{2}{*}{ Material } & $\begin{array}{c}\text { Heat treatment } \\
\text { condition }\end{array}$ & $\begin{array}{c}\text { Experiment } \\
\text { Tensile } \\
\text { test }\end{array}$ & $\mathrm{OIM}$ & $\begin{array}{c}\text { Bulge } \\
\text { test }\end{array}$ & Continuum & $\begin{array}{c}\text { Continuum } \\
+\mathrm{CP}\end{array}$ \\
\hline $\mathrm{Cu}$ Alloy & $1 \mathrm{~h} / 600^{\circ} \mathrm{C}$ & $\mathrm{O}$ & $\mathrm{O}$ & $\mathrm{O}$ & $\mathrm{O}$ & $\mathrm{O}$ \\
\hline $\mathrm{Nb}$ & $3 \mathrm{~h} / 800^{\circ} \mathrm{C}$ & $\mathrm{O} *[9]$ & $\mathrm{O} *[9]$ & $\mathrm{X}$ & $\mathrm{O} *[9]$ & $\mathrm{O}$ \\
\hline $\mathrm{Nb}$ & $2 \mathrm{~h} / 1000^{\circ} \mathrm{C}$ & $\mathrm{O} *[9]$ & $\mathrm{O} *[9]$ & $\mathrm{O} *[9]$ & $\mathrm{O} *[9]$ & $\mathrm{O}$ \\
\hline $\mathrm{Nb}$ & $3 \mathrm{~h} / 800^{\circ} \mathrm{C}+2 \mathrm{~h} / 1000^{\circ} \mathrm{C}$ & $\mathrm{O}$ & $\mathrm{O}$ & $\mathrm{X}$ & $\mathrm{O}$ & $\mathrm{O}$ \\
\hline $\mathrm{Nb}$ & $2 \mathrm{~h} / 1000^{\circ} \mathrm{C} \times 3$ & $\mathrm{O}$ & $\mathrm{O}$ & $\mathrm{X}$ & $\mathrm{O}$ & $\mathrm{O}$ \\
\hline \hline
\end{tabular}

O: performed in this study

$\mathrm{O} *$ : performed in previous studies

$\mathrm{X}$ : not performed 
Table III Material parameters for CP-FEM

\begin{tabular}{cccccc}
\hline \hline Materials & Heat treatment & $g_{0}$ & $h_{0}$ & $g_{s}$ & $a$ \\
\hline Cu Alloy & $1 \mathrm{~h} / 600^{\circ} \mathrm{C}$ & 8 & 445 & 1005 & 26 \\
\hline \multirow{3}{*}{$\mathrm{Nb}$} & $3 \mathrm{~h} / 800^{\circ} \mathrm{C}$ & 60 & 800 & 105 & 1.5 \\
\cline { 2 - 6 } & $2 \mathrm{~h} / 1000^{\circ} \mathrm{C}$ & 50 & 810 & 95 & 1.45 \\
\cline { 2 - 6 } & $3 \mathrm{~h} / 800^{\circ} \mathrm{C}+2 \mathrm{~h} / 1000^{\circ} \mathrm{C}$ & 50 & 800 & 150 & 3.5 \\
\cline { 2 - 6 } & $2 \mathrm{~h} / 1000^{\circ} \mathrm{C} \mathrm{X} \mathrm{3}$ & 30 & 1000 & 120 & 3 \\
\hline \hline
\end{tabular}


Table IV Summary of plastic properties for inputs to the macroscopic model for the $\mathrm{Cu}$ alloy and $\mathrm{Nb}$ tubes

\begin{tabular}{cccc}
\hline \hline Material & Method & $K$ & $n$ \\
\hline \multirow{2}{*}{$\mathrm{Cu}\left(1 \mathrm{~h} / 600^{\circ} \mathrm{C}\right)$} & Tensile test & 561.20 & 0.460 \\
\cline { 2 - 4 } & Bulge test & 436.40 & 0.378 \\
\cline { 2 - 4 } & CP-FEM & 480.59 & 0.410 \\
\hline \multirow{2}{*}{$\mathrm{Nb}\left(2 \mathrm{~h} / 1000^{\circ} \mathrm{C}\right)$} & Tensile test & 314.18 & 0.191 \\
\cline { 2 - 4 } & Bulge test & 299.99 & 0.157 \\
\cline { 2 - 4 } & CP-FEM & 291.02 & 0.145 \\
\hline \hline
\end{tabular}


Table V Summary of plastic properties for inputs to the macroscopic model for $\mathrm{Nb}$ heat treated at various conditions

\begin{tabular}{cccc}
\hline Material & Method & $K$ & $n$ \\
\hline \multirow{2}{*}{$\mathrm{Nb}\left(3 \mathrm{~h} / 800^{\circ} \mathrm{C}\right)$} & Tensile test & 331.61 & 0.145 \\
\cline { 2 - 4 } & CP-FEM & 373.33 & 0.158 \\
\hline \multirow{2}{*}{$\mathrm{Nb}\left(3 \mathrm{~h} / 800^{\circ} \mathrm{C}+2 \mathrm{~h} / 1000^{\circ} \mathrm{C}\right)$} & Tensile test & 325.70 & 0.200 \\
\cline { 2 - 4 } & CP-FEM & 366.54 & 0.200 \\
\hline $\mathrm{Nb}\left(2 \mathrm{~h} / 1000^{\circ} \mathrm{C} \mathrm{X} \mathrm{3)}\right.$ & Tensile test & 307.46 & 0.234 \\
\cline { 2 - 4 } & CP-FEM & 360.49 & 0.212 \\
\hline \hline
\end{tabular}




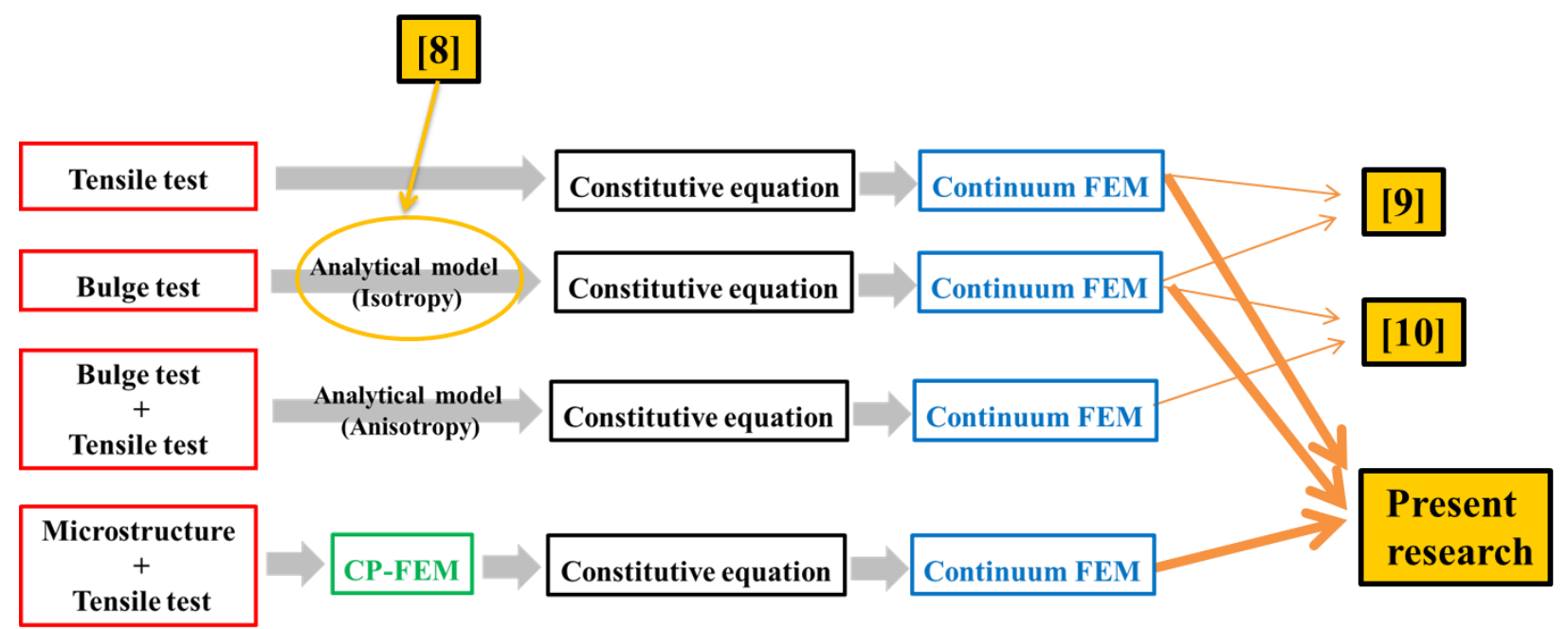

Figure 1. Evolution of our research on the hydroforming of tubular materials 


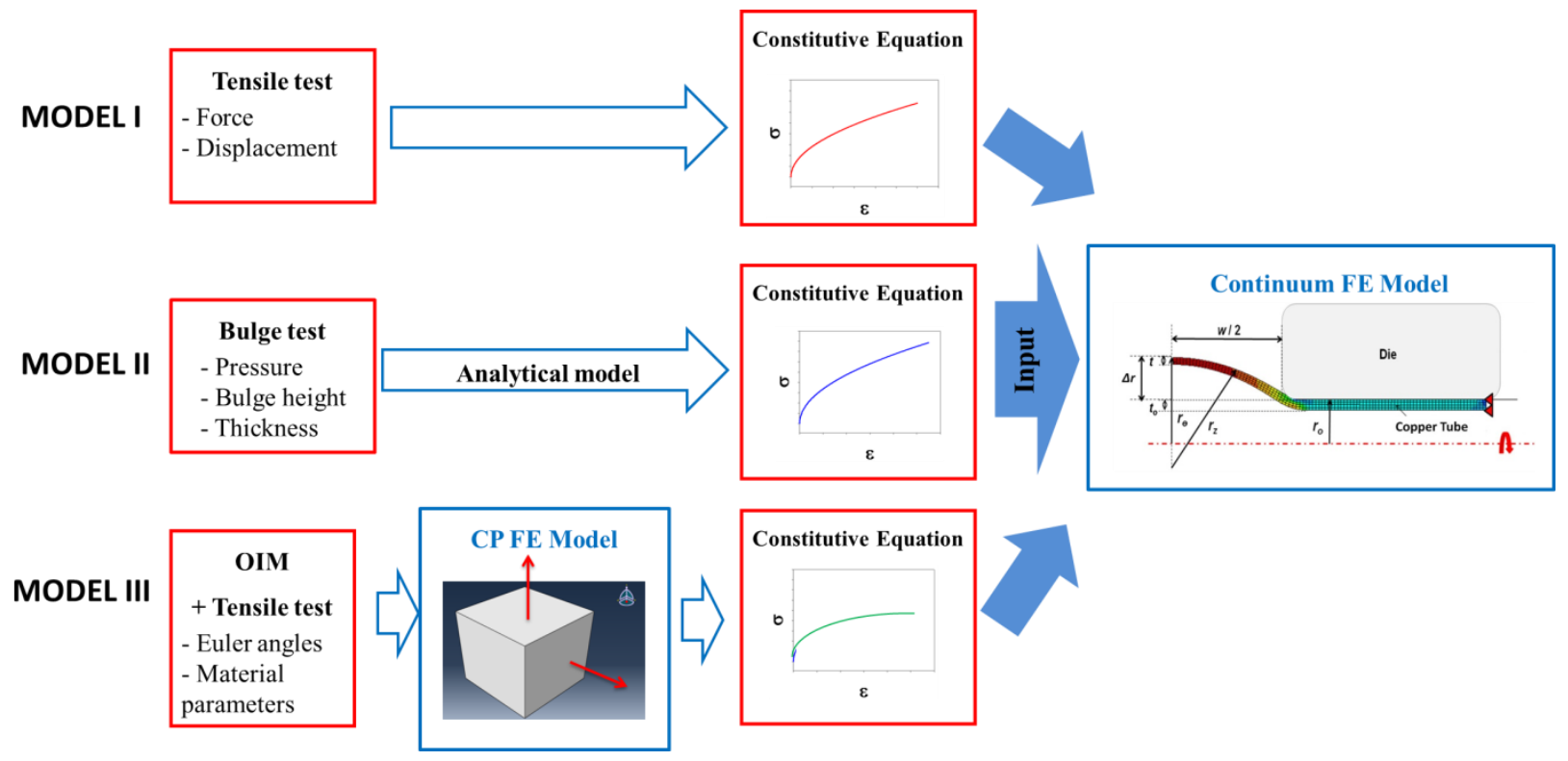

Figure 2. Outline of the present paper 


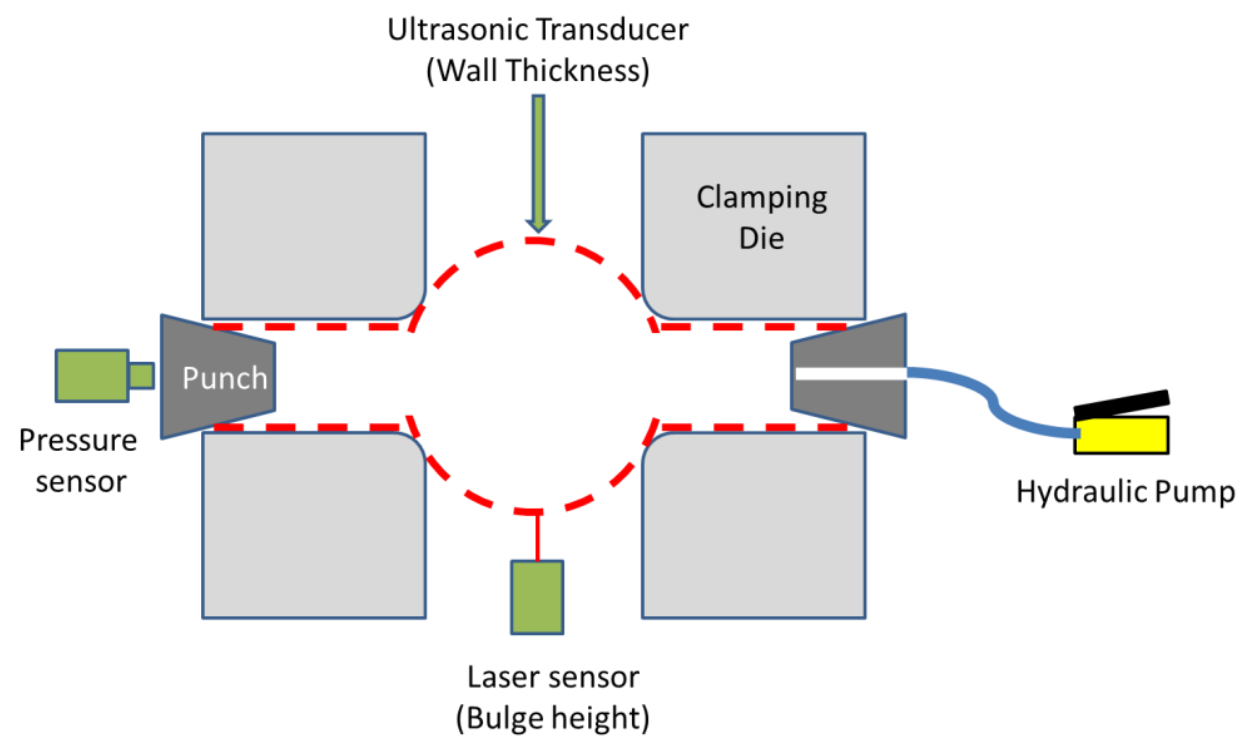

Figure 3. Tube bulge test system 


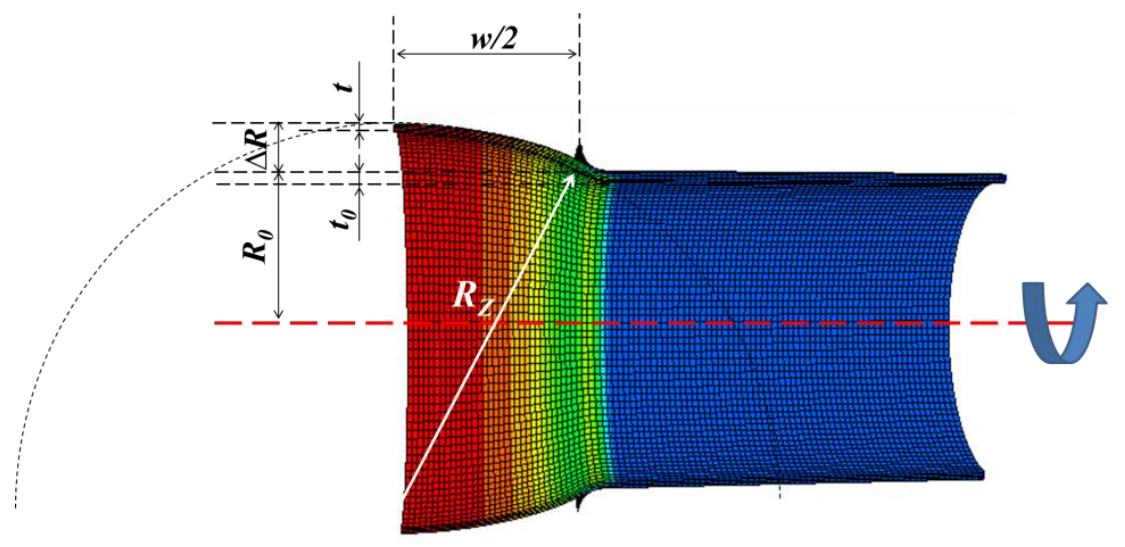

Figure 4. Parameters for the analysis of the bulge test results 


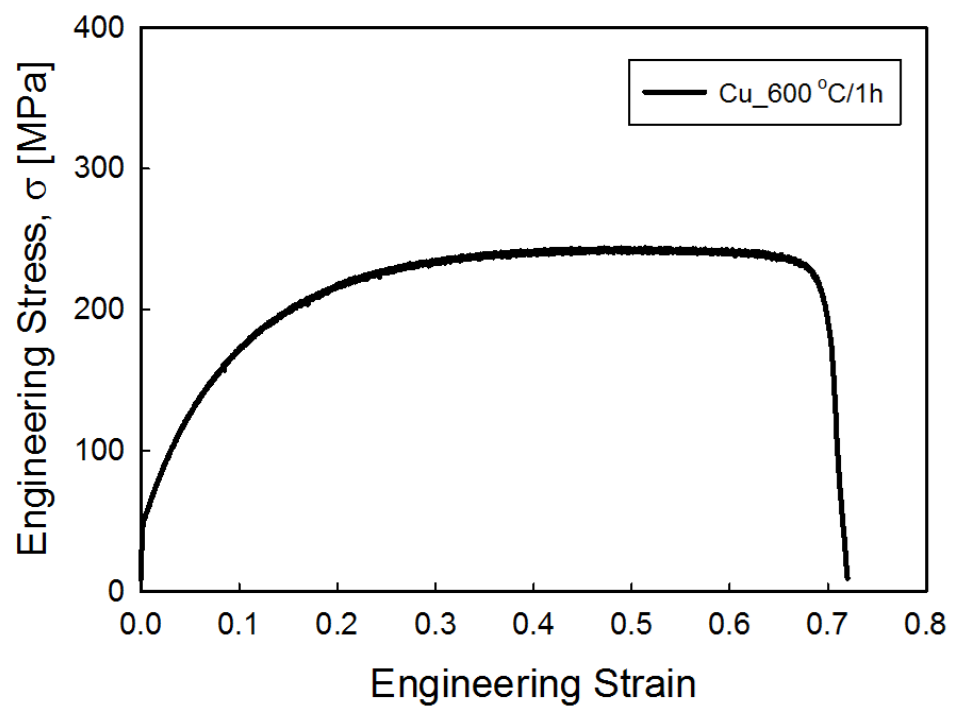

(a)

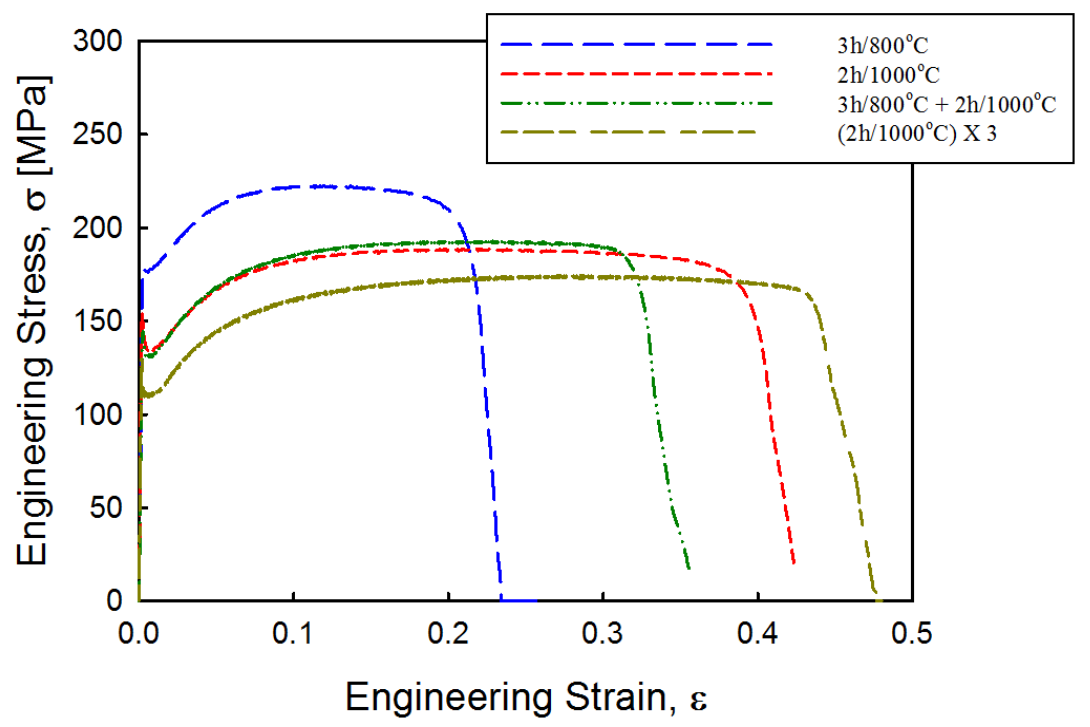

(b)

Figure 5. Tensile test results for (a) $\mathrm{Cu}$ alloy and (b) $\mathrm{Nb}$ samples 


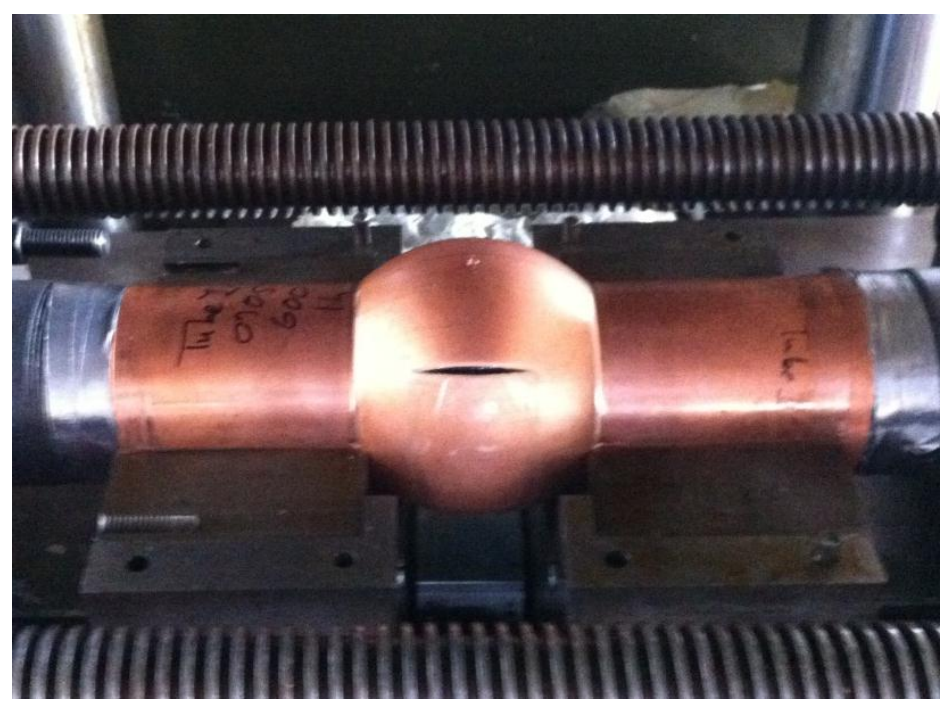

Figure 6. The deformed $\mathrm{Cu}$ alloy tube after bulge testing 


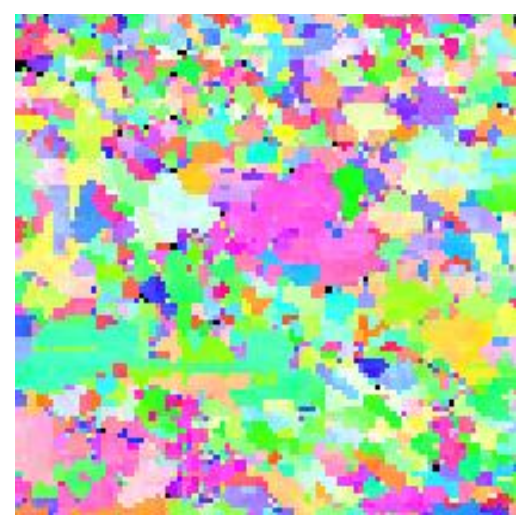

(a)
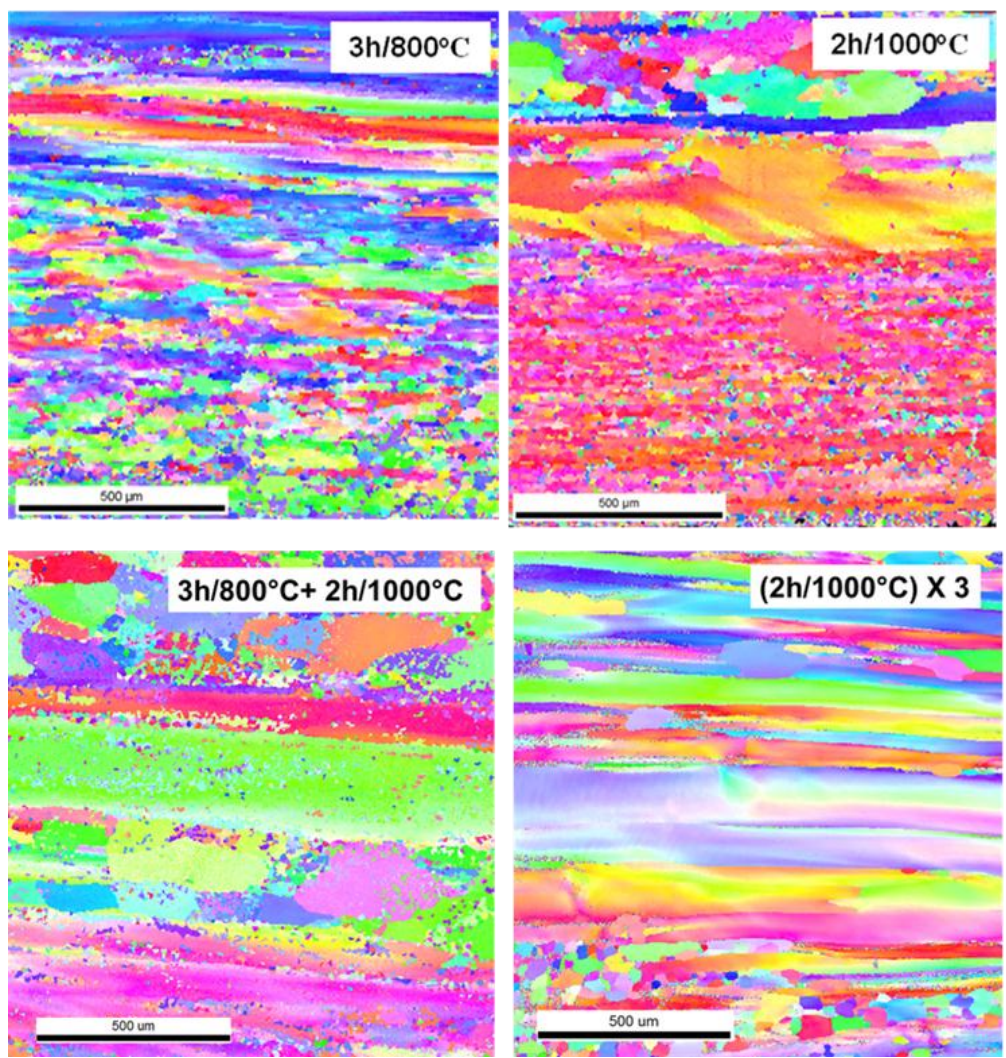

(b)

Figure 7. Orientation maps of (a) $\mathrm{Cu}$ alloy heat treated for $1 \mathrm{~h} / 600^{\circ} \mathrm{C}$, and (b) $\mathrm{Nb}$ heat treated at various conditions 

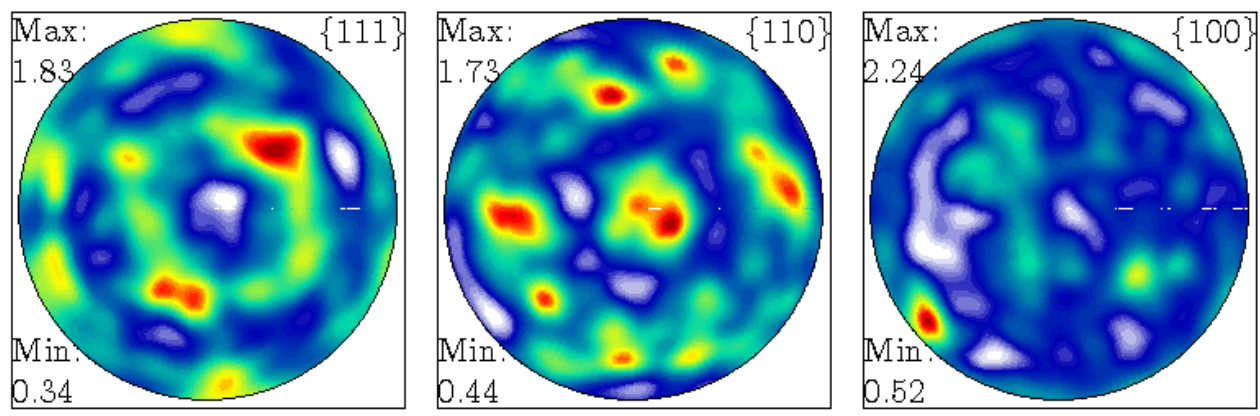

(a)
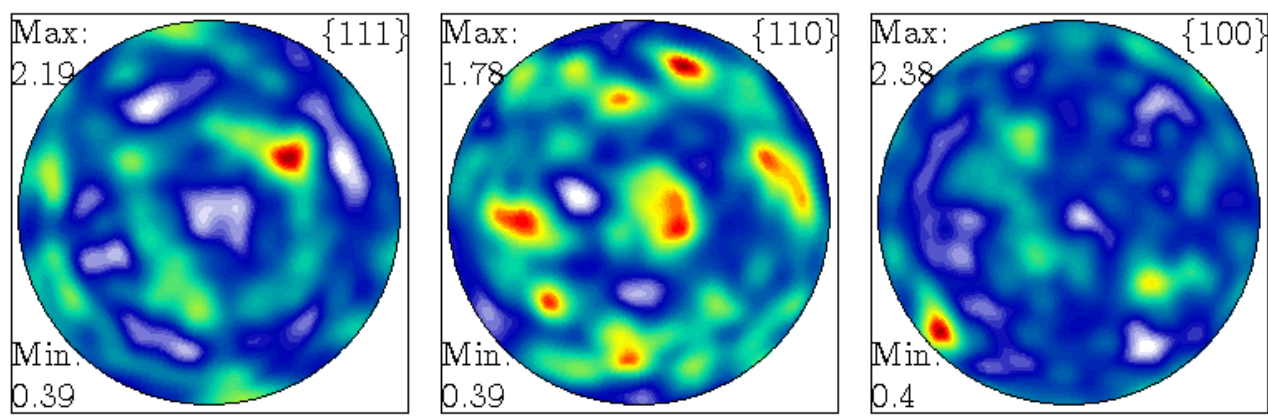

(b)

Figure 8. Pole figures of the $\mathrm{Cu}$ alloy heat treated for $1 \mathrm{~h} / 600^{\circ} \mathrm{C}$ : (a) measured and (b) selected orientations 

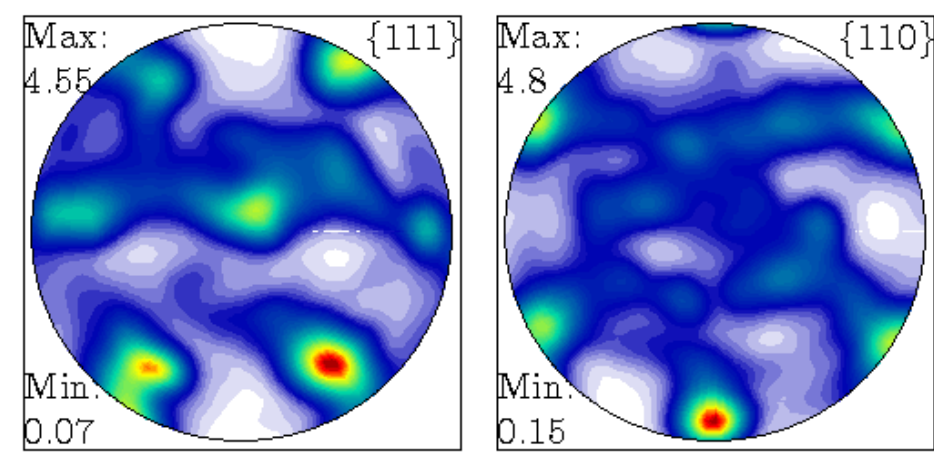

(a)
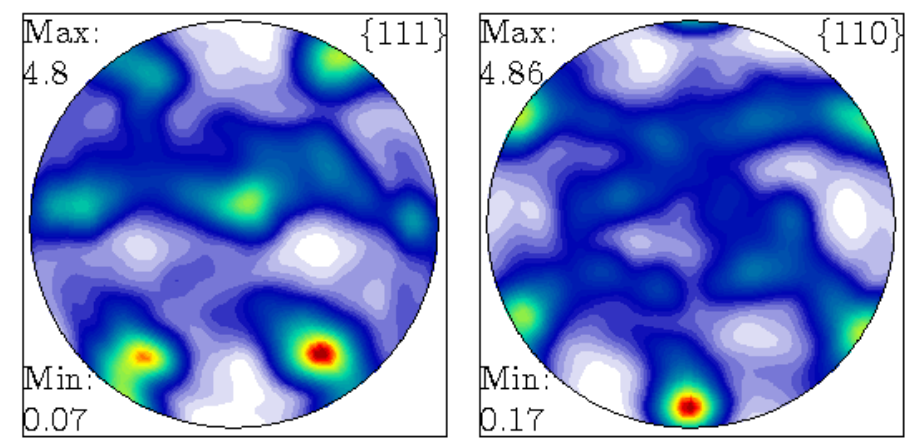

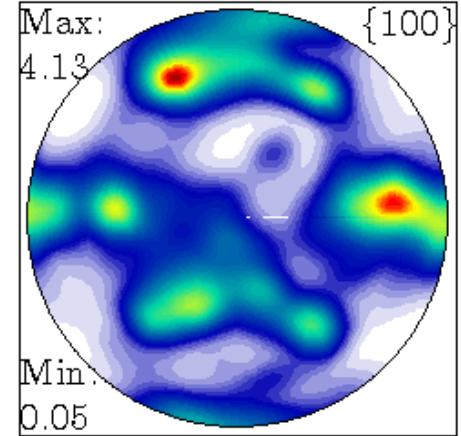

0.05

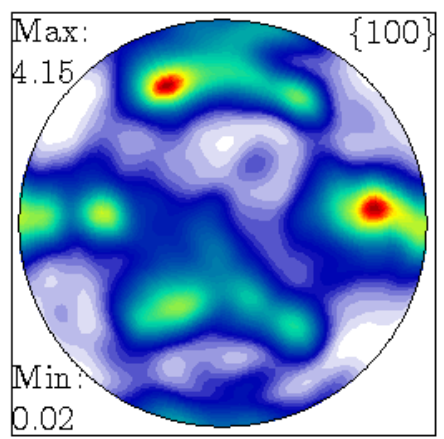

(b)

Figure 9. Pole figures of the $\mathrm{Nb}$ heat treated for $3 \mathrm{~h} / 800^{\circ} \mathrm{C}$ : (a) measured and (b) selected orientations [8] 

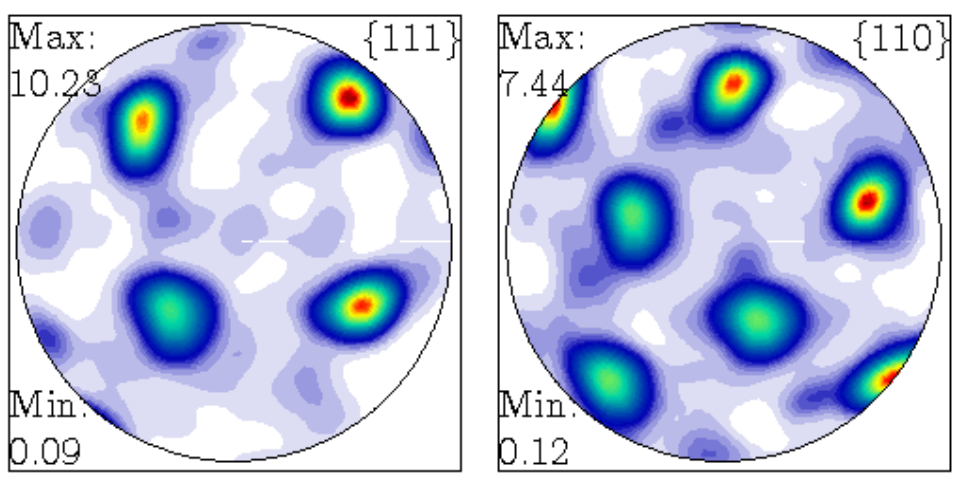

(a)
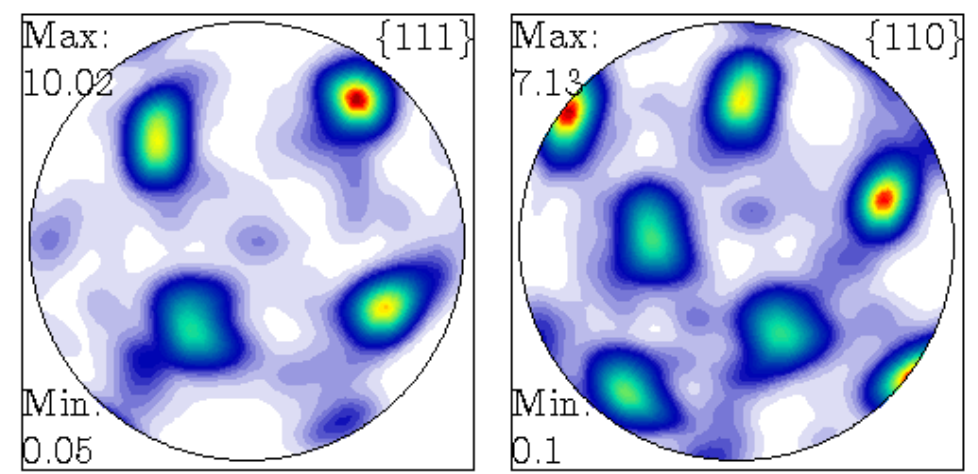

(b)
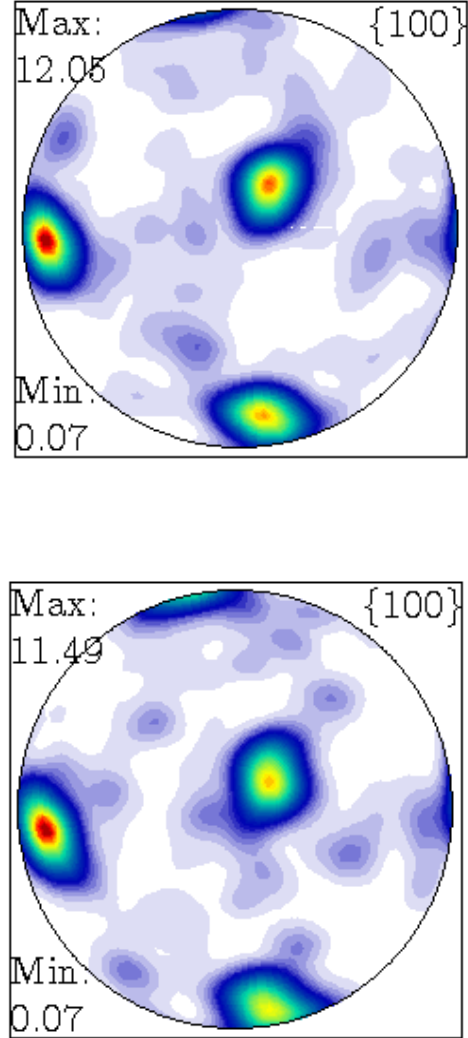

0.07

Figure 10. Pole figures of the $\mathrm{Nb}$ heat treated for $2 \mathrm{~h} / 1000^{\circ} \mathrm{C}$ : (a) measured and (b) selected orientations [8] 

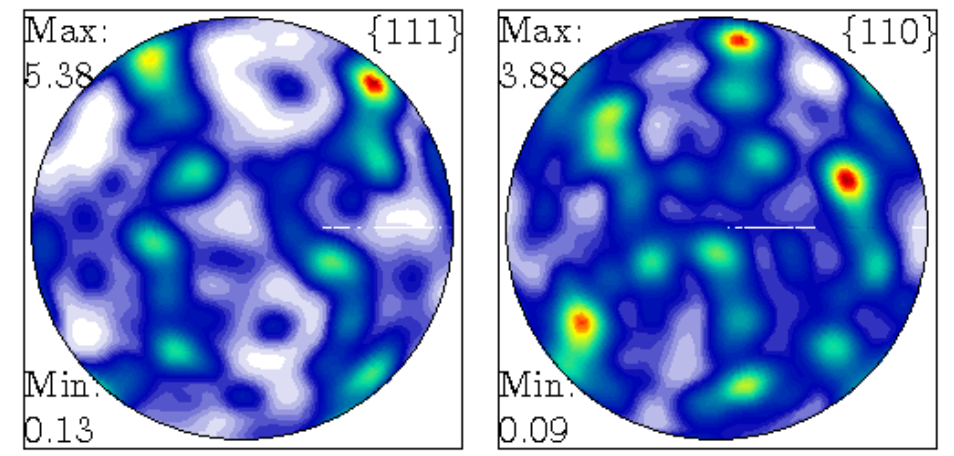

(a)
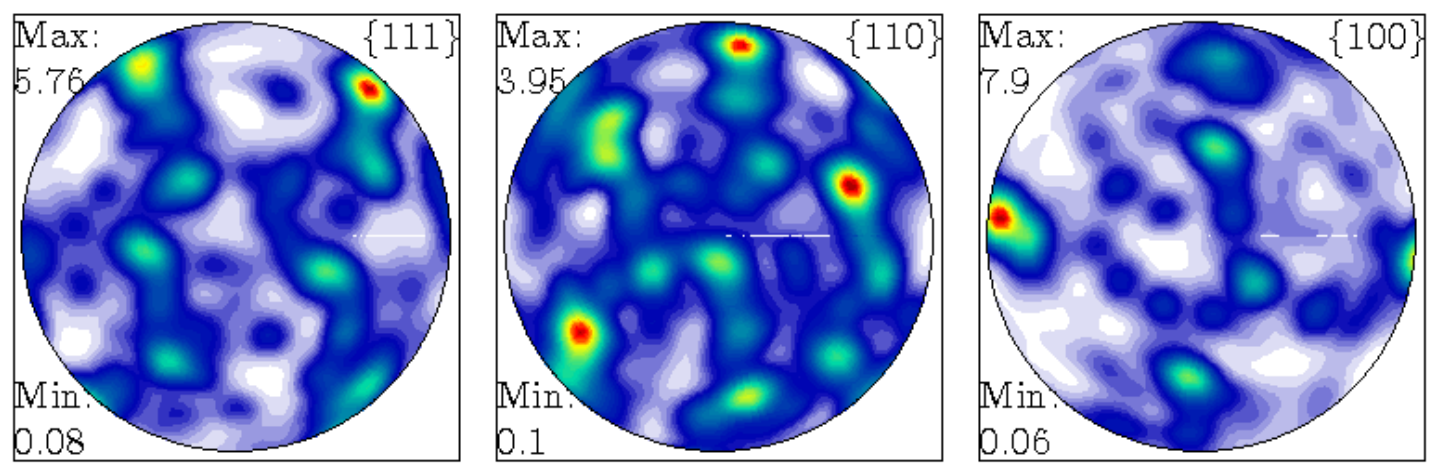

(b)

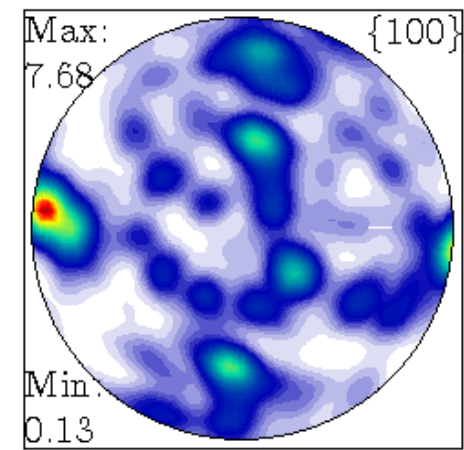

0.13

0.06

\section{)}

Figure 11. Pole figures of the $\mathrm{Nb}$ heat treated for $3 \mathrm{~h} / 800^{\circ} \mathrm{C}+2 \mathrm{~h} / 1000^{\circ} \mathrm{C}$ : (a) measured and (b) selected orientations 

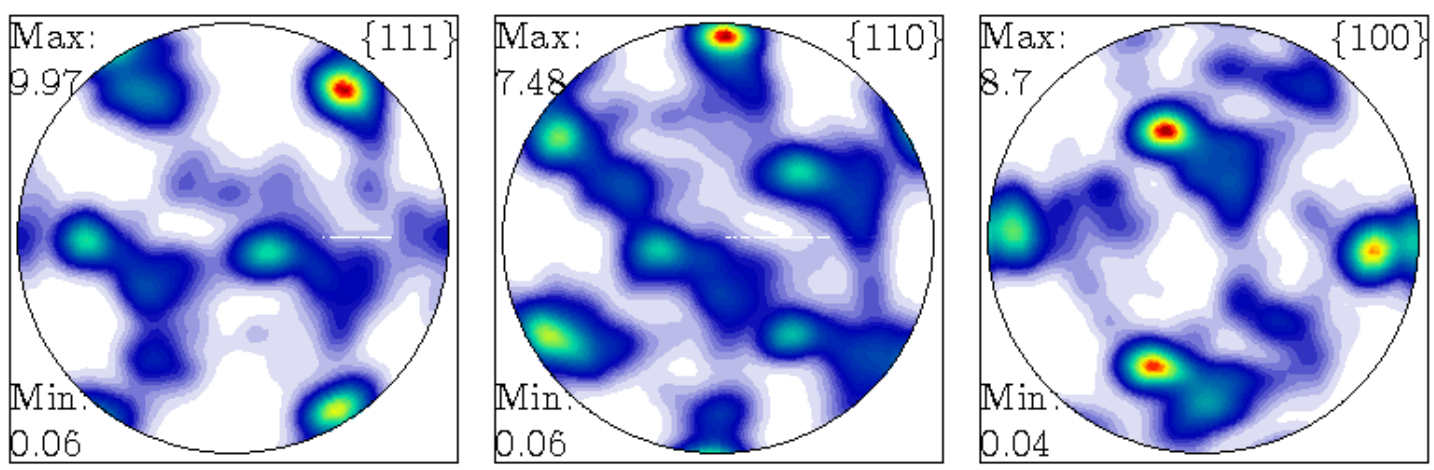

(a)
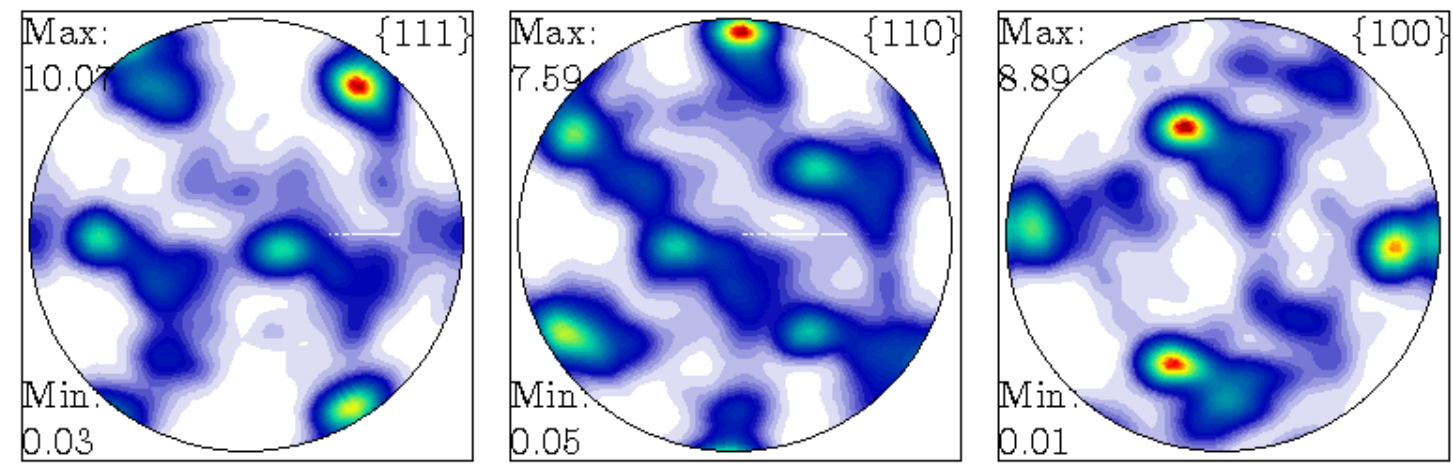

(b)

Figure 12. Pole figures of the $\mathrm{Nb}$ heat treated for $2 \mathrm{~h} / 1000^{\circ} \mathrm{C} \mathrm{X} 3$ : (a) measured and (b) selected orientations 


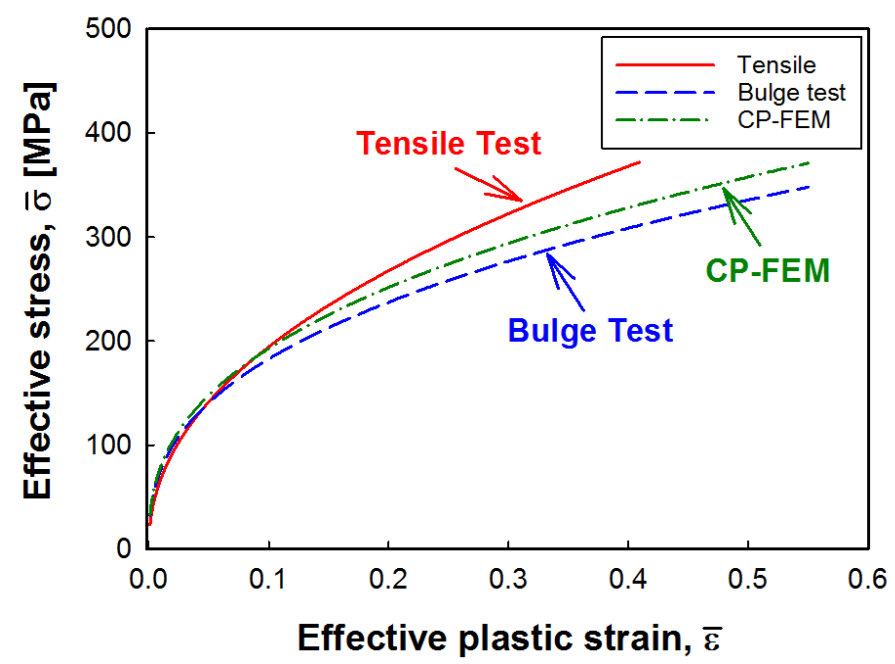

Figure 13. Effective strain-stress curves obtained from the tensile testing, bulge testing and CPFEM simulation of $\mathrm{Cu}$ alloy heat treated for $1 \mathrm{~h} / 600^{\circ} \mathrm{C}$ 


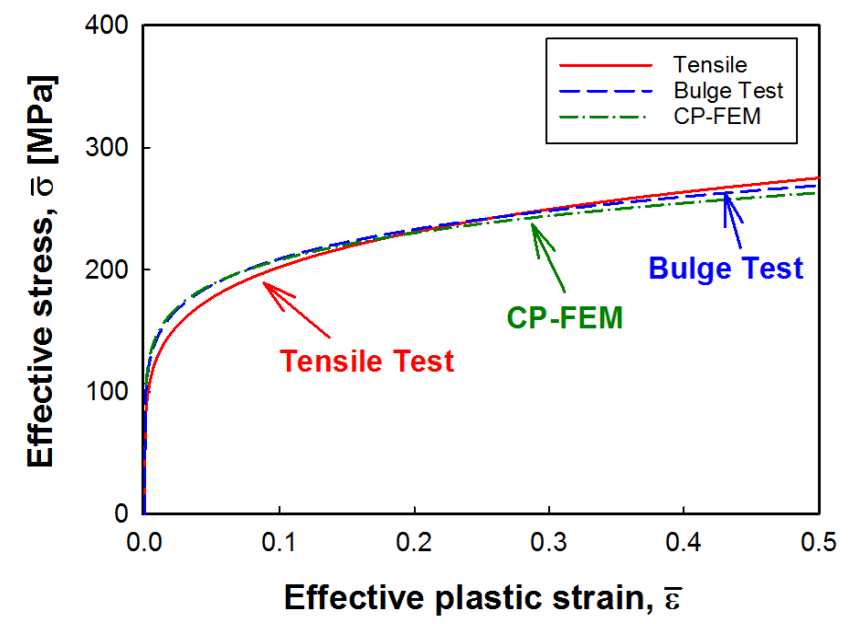

Figure 14. Effective strain-stress curves obtained from the tensile testing, bulge testing and CPFEM simulation of $\mathrm{Nb}$ heat treated for $2 \mathrm{~h} / 1000^{\circ} \mathrm{C}$ 


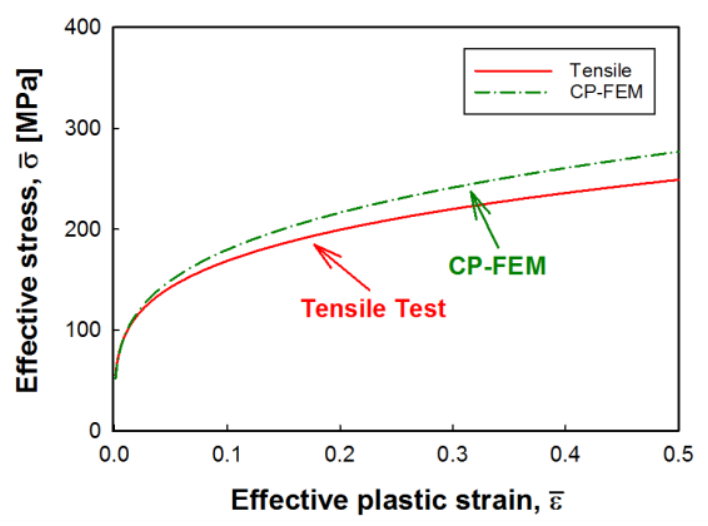

(a)

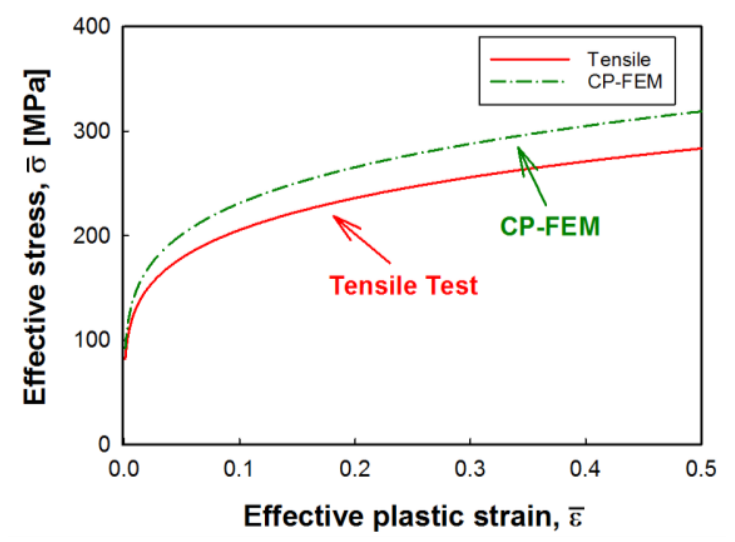

(b)

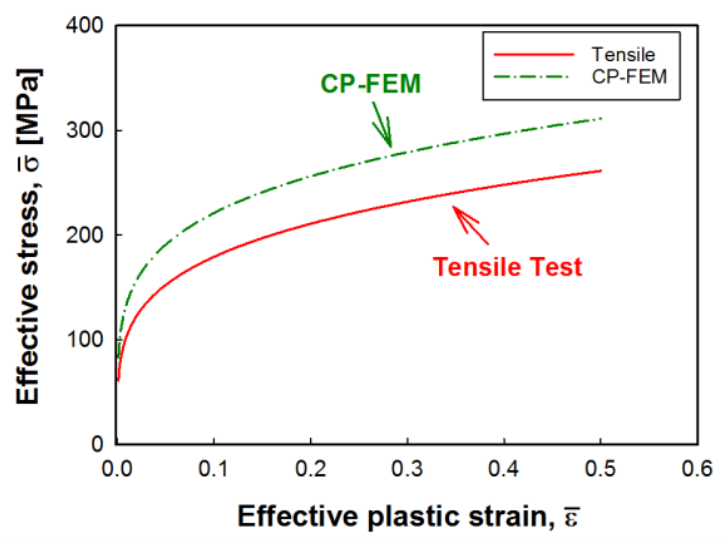

(c)

Figure 15. Effective strain-stress curves obtained from the tensile testing and CP-FEM simulation of $\mathrm{Nb}$ heat treated for (a) $3 \mathrm{~h} / 800^{\circ} \mathrm{C}$, (b) $3 \mathrm{~h} / 800^{\circ} \mathrm{C}+2 \mathrm{~h} / 1000^{\circ} \mathrm{C}$ and (c) $2 \mathrm{~h} / 1000^{\circ} \mathrm{C} \mathrm{X} 3$ 

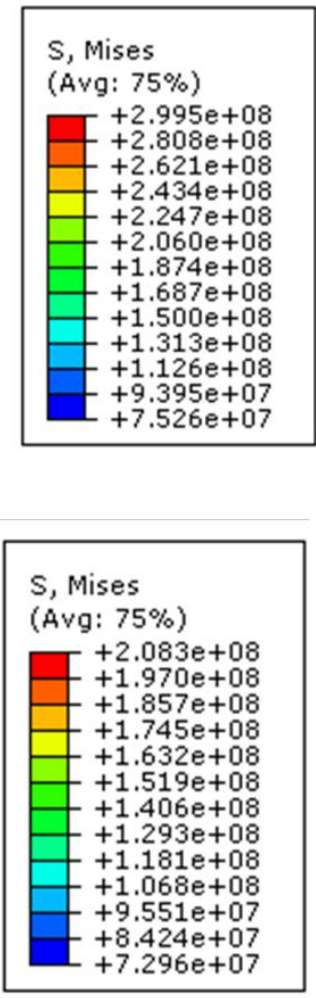

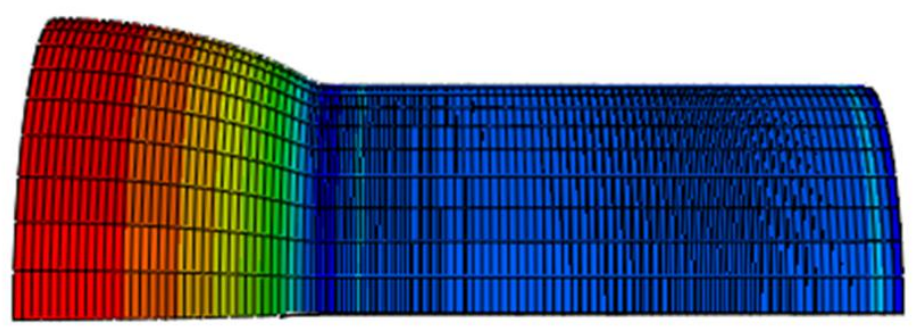

(a)

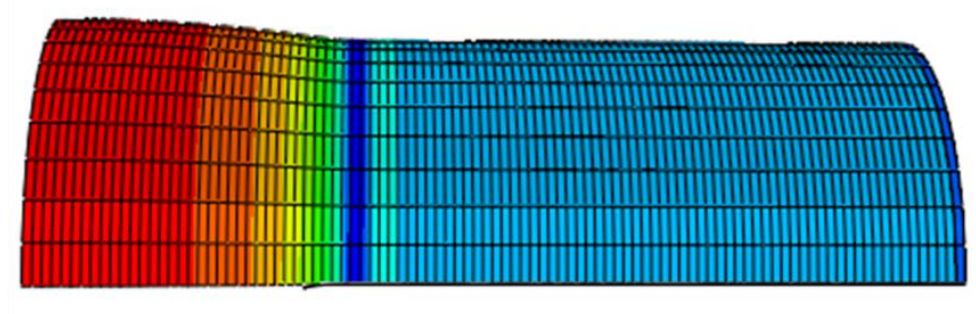

(b)

Figure 16. Contour of von Mises stress of (a) $\mathrm{Cu}$ alloy and (b) $\mathrm{Nb}$ heat treated for $2 \mathrm{~h} / 1000^{\circ} \mathrm{C}$ 

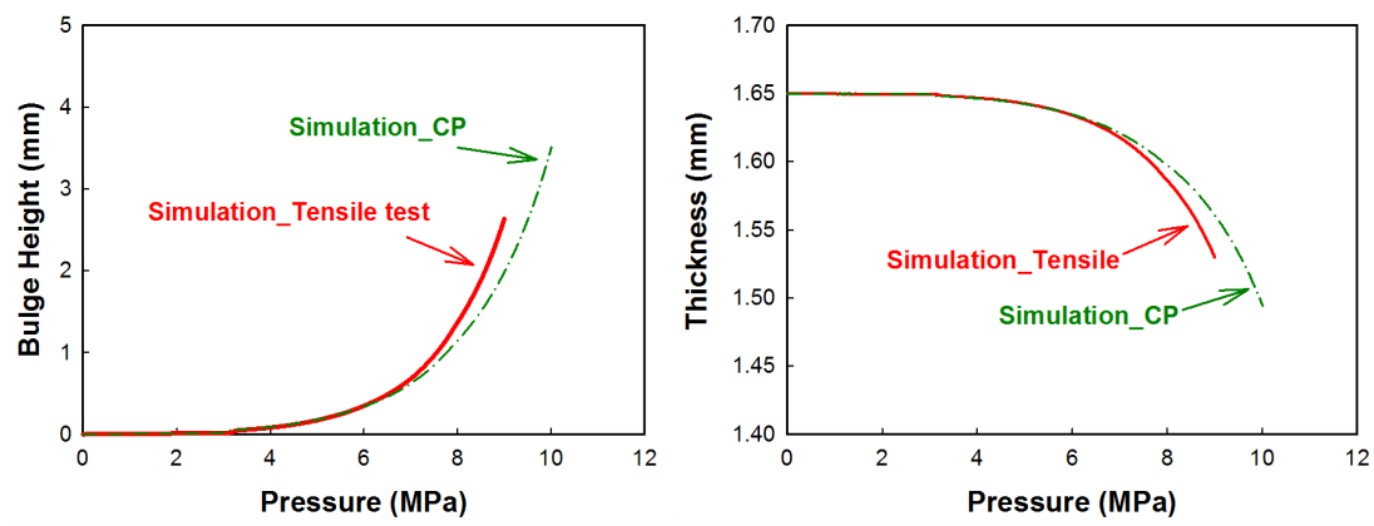

(a)
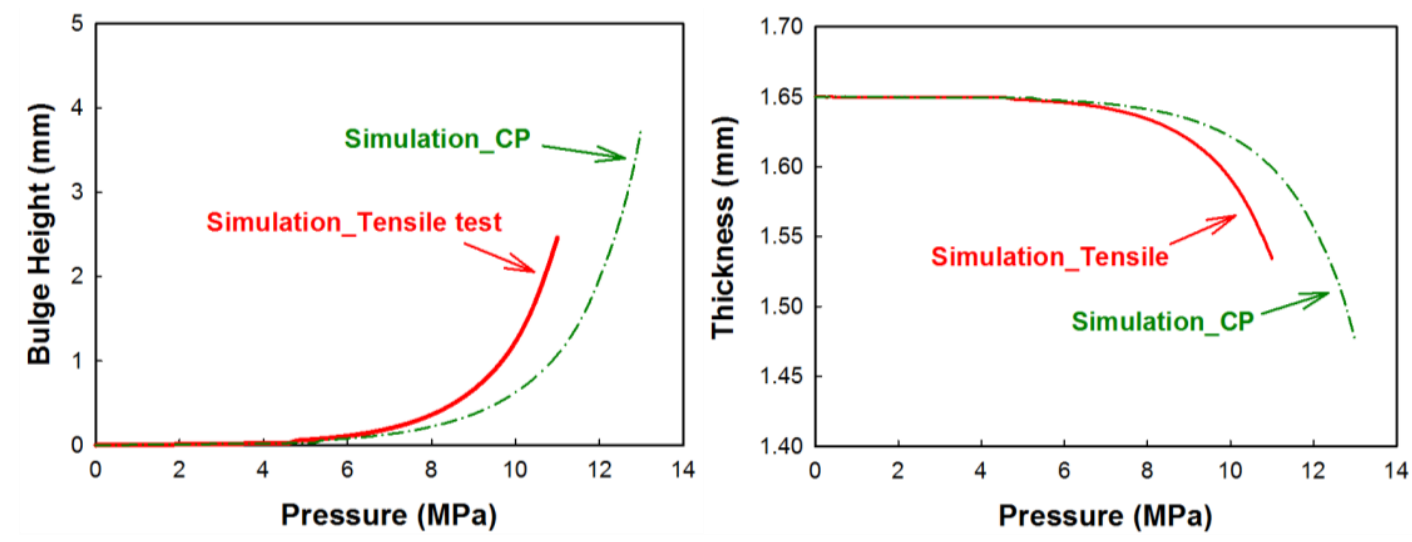

(b)
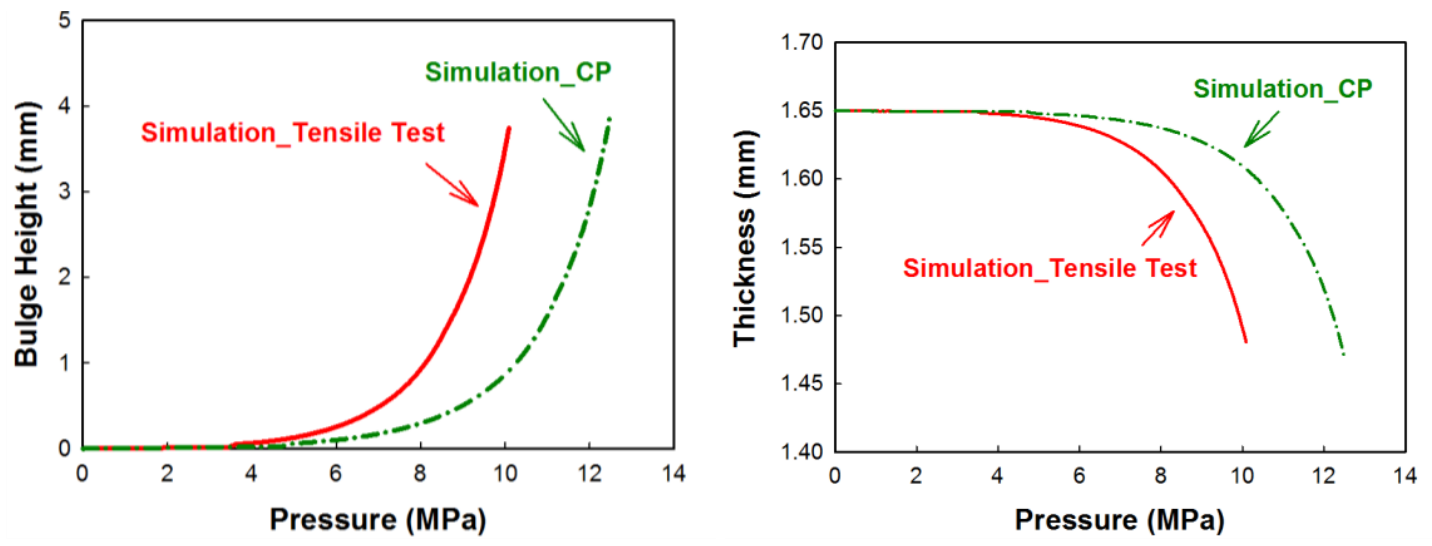

(c)

Figure 17. Simulation results of $\mathrm{Nb}$ heat treated for (a) $3 \mathrm{~h} / 800^{\circ} \mathrm{C}$, (b) $3 \mathrm{~h} / 800^{\circ} \mathrm{C}+2 \mathrm{~h} / 1000^{\circ} \mathrm{C}$ and (c) $2 \mathrm{~h} / 1000^{\circ} \mathrm{C} \mathrm{X} 3$ 

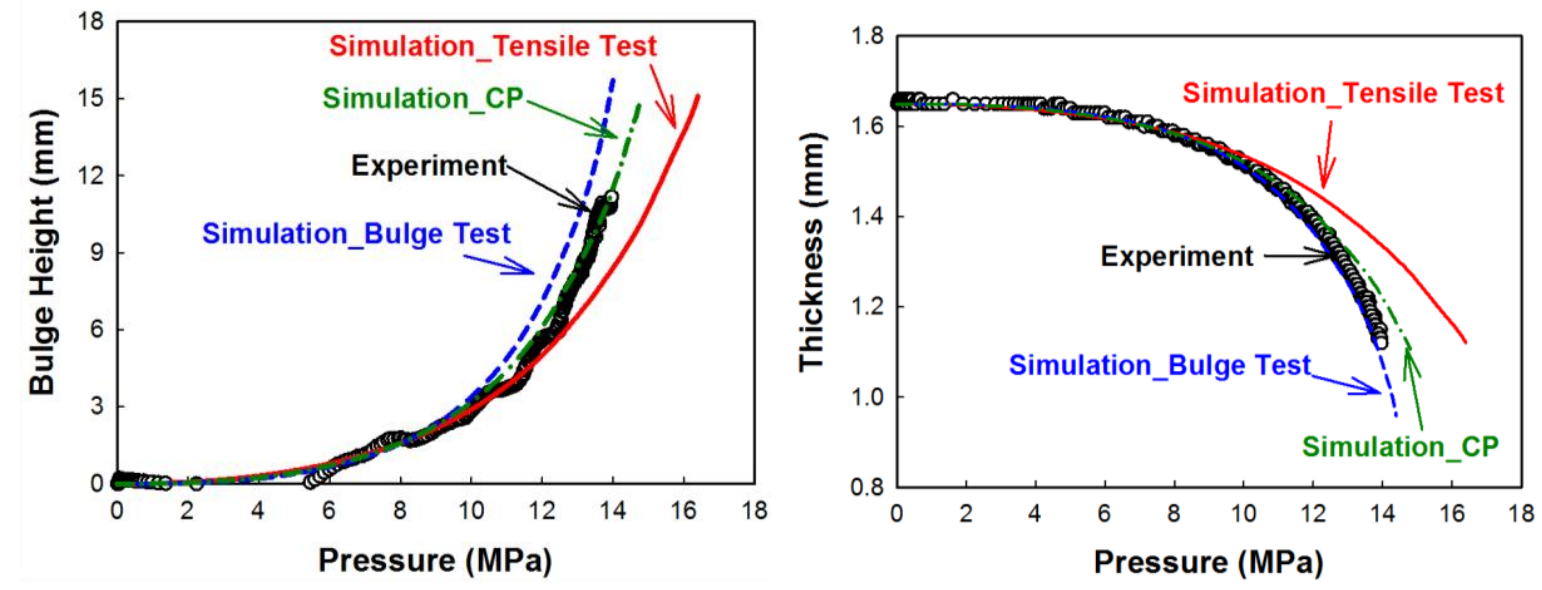

(a)
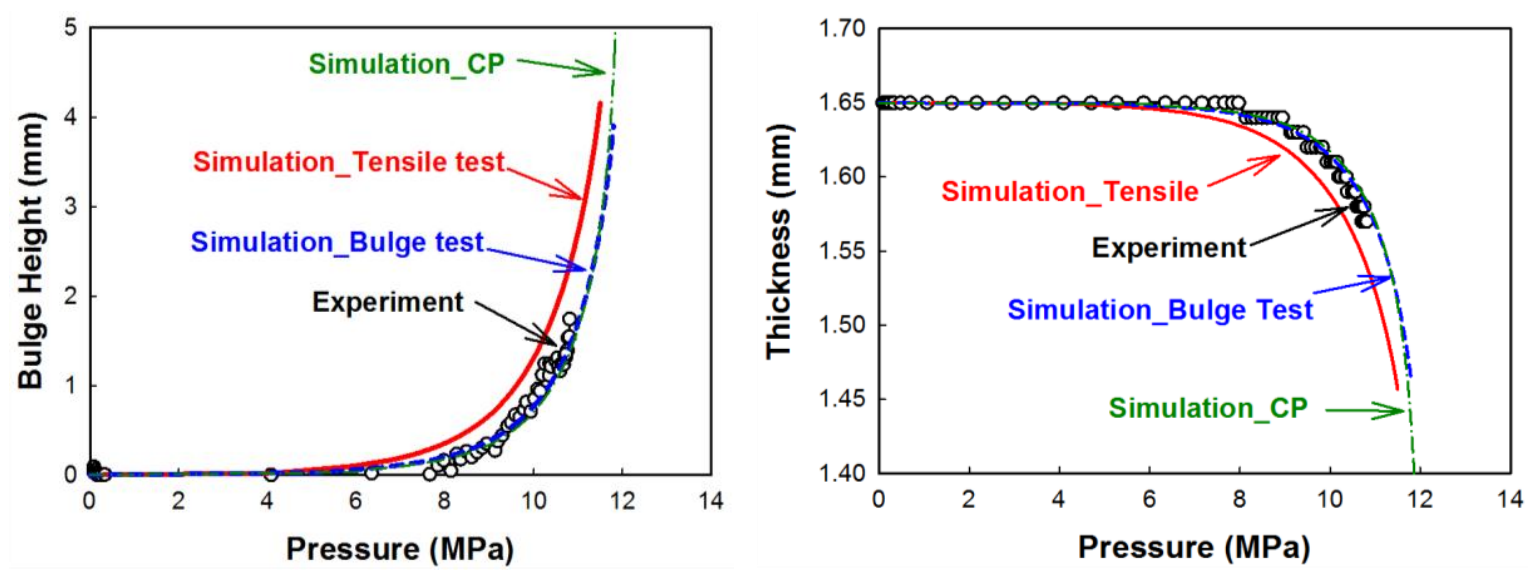

(b)

Figure 18. Simulation results of (a) $\mathrm{Cu}$ alloy heat treated for $1 \mathrm{~h} / 600^{\circ} \mathrm{C} \mathrm{(b)} \mathrm{Nb}$ heat treated for $2 \mathrm{~h} / 1000^{\circ} \mathrm{C}$ 